This item was submitted to Loughborough's Research Repository by the author.

Items in Figshare are protected by copyright, with all rights reserved, unless otherwise indicated.

\title{
Experimental and numerical investigation of the effect of asymmetry on the residual strength of a composite sandwich panel
}

\section{PLEASE CITE THE PUBLISHED VERSION}

http://dx.doi.org/10.1177/1099636215577348

\section{PUBLISHER}

SAGE Publications / @ The Author(s)

VERSION

AM (Accepted Manuscript)

\section{PUBLISHER STATEMENT}

This work is made available according to the conditions of the Creative Commons Attribution-NonCommercialNoDerivatives 4.0 International (CC BY-NC-ND 4.0) licence. Full details of this licence are available at: https://creativecommons.org/licenses/by-nc-nd/4.0/

\section{LICENCE}

CC BY-NC-ND 4.0

\section{REPOSITORY RECORD}

James, Chris T., Andrew Watson, and Paul Cunningham. 2015. "Experimental and Numerical Investigation of the Effect of Asymmetry on the Residual Strength of a Composite Sandwich Panel". figshare. https://hdl.handle.net/2134/17239. 


\title{
Experimental and Numerical Investigation of the Effect of Asymmetry on the Residual Strength of a Composite Sandwich Panel
}

\author{
Chris T James*, Paul R Cunningham, Andrew Watson \\ Department of Aeronautical and Automotive Engineering, \\ Loughborough University, Epinal Way, Loughborough, Leics', LE11 3TU, UK \\ *Author for correspondence: c.james@lboro.ac.uk
}

\begin{abstract}
Asymmetric sandwich panels with skins of differing thickness are subjected to various degrees of damage via quasi-static indentation before compressive loading to failure. These are compared with panels with skins of equal thickness. The experiments show that the asymmetric panels experience an improvement in strength with small amounts of indentation compared with undamaged asymmetric panels, and for more severe damage, show greater residual strength than the symmetric panels. The two configurations are numerically modelled using Abaqus, including inter- and intra-laminar damage, and core crushing. The strength predictions from the models agree well with the experiments.
\end{abstract}

\section{Keywords}

Numerical modelling; composites; sandwich panels; CAI; damage modelling

\section{Introduction}

Sandwich panels featuring composite skins and low-density cores are seeing increasing use in aerospace, marine and other industrial applications due to their improved specific strength and stiffness, and damage resistance, as compared with traditional monolithic composite structures (1). However, they remain highly vulnerable to significant reductions in strength resulting from lowvelocity impact damage (1).

Numerical modelling is an extremely useful tool for designers, as it eliminates much physical testing during design, prototyping and validation of new structures. One specific advantage for modelling compression problems is that it can remove some of the uncertainty that results from experiments. Data scatter and poor repeatability in CAI experiments is a well-documented problem $(2,3)$, due to compressive failure modes being dominated by elastic instability, with their inherent sensitivity to structural and experimental imperfections (4). This uncertainty results in a degree of inefficiency in structural design as higher factors of safety are required to provide confidence using composites over traditional metallic samples. Accurate prediction of damage and failure in composite materials is an area of considerable interest $(5,6)$, and there remains no standard approach for evaluating the CAI strength of composite sandwich panels (7).

A recent study by Zhou et al (8) has suggested that introducing minor asymmetry to a sandwich via the use of a thinner skin on the distal (non-impacted) face of a sandwich panel can improve its damage tolerance over a conventional configuration using skins of equal thickness on both sides. 
They found that when the thicker skin was impact damaged, the reduction in stiffness in that skin removed the bending moment caused by the uneven axial stiffness of the two skins. The stabilising effect of the impact damage thus results in improved damage tolerance compared to the symmetrical panels.

This paper describes an experimental and numerical study to further study this behaviour. Symmetric and asymmetric panels are damaged via quasi-static indentation which are then subjected to edge compression. A numerical model, which accounts for intra- and interlaminar skin damage and core crushing, is also presented to simulate the results of the experimental phase, using the commercial finite element software Abaqus/Explicit. The strength results from the model are then compared with the experimental data.

\section{Sample preparation}

Two panel configurations were tested: one with skins of equal thickness (henceforth designated as 'symmetric'), using a quasi-isotropic lay-up of [-45/0/45/90 $]_{s}$ for both skins. The second configuration uses skins of unequal thickness (designated as 'asymmetric'), with the thicker skin using the same lay-up as for the symmetric panel skins, and thinner skin using a multi-directional lay-up of [45/0/45]s. In the case of the asymmetric panel, the thicker skin will be used as the impacted (and thus damaged) side. Both panel configurations use a $12.7 \mathrm{~mm}$ (nominal; mean measured thickness of 12.163mm) thick aluminium honeycomb core (HexWEB CRIII 3/16 5052 4.4). The skins are produced, in all cases, from high-strength carbon fibre uni-directional prepregs, utilising an out-ofautoclave cured epoxy resin, and T700S carbon fibre reinforcement with 12K roving (M77/42\%/UD90/CHS). The panel configurations and materials are based on (but not identical to) those used by Zhou et al (8); the planar dimensions of the panels are based on the requirements of ASTM D7137 (9) for the CAI testing of monolithic composite plates, giving nominal dimensions of $150 \times 100 \mathrm{~mm}( \pm 1 \mathrm{~mm})$, with the longer dimension parallel to the loading direction under compression.

The skins were cured according to a suggested cycle at $100^{\circ} \mathrm{C}$ for 40 minutes, with a temperature ramp rate of $2^{\circ} \mathrm{C} /$ minute. The nominal ply thickness was given by the supplier to be $0.103 \mathrm{~mm}(10)$. Measurement of a sample of cured skins gives an average thickness of $0.853 \mathrm{~mm}$ for the 8-ply quasiisotropic skins, and $0.644 \mathrm{~mm}$ for the 6-ply multi-directional skins. The skins are bonded to the honeycomb using Redux 609 adhesive. These are cured at $120^{\circ} \mathrm{C}$ for one hour, with a temperature ramp rate of $5^{\circ} \mathrm{C} /$ minute, in accordance with the supplier's recommendations (10). The panels are assembled such that the $\mathrm{W}$-direction of the honeycomb is parallel with the $0^{\circ}$ fibre direction on the skins, and also the loading direction for the compressive tests. The ends of all panels are then reinforced by potting with Gurit Prime 20LV epoxy resin, cured at room temperature for 24 hours.

A number of panels were produced in the above manner for edge compression tests for panels subjected to varying amounts of transverse quasi-static indentation damage as well as undamaged panels. Data spread in the ultimate strength is expected, so repeat tests will be used here (5 tests per load level minimum - including undamaged, per panel configuration). Aside from the sandwich panels, a number of uni-directional material specimens were prepared from the same roll of composite material to gather input data for the numerical model. Time and resource constraints meant that a complete set of data could not be collected. The tests performed were uniaxial tensile tests in accordance with ASTM D3039 (11), giving the elastic modulus and tensile strength in both longitudinal and transverse directions (E1, E2, $\sigma 1+$ and $\sigma 2+$ ), as well as the in-plane major Poisson's 
ratio (v12). A uniaxial compressive test using a sample from ASTM D3410 (12), modified to suit the supporting fixture specified in ASTM D694 (13) was also performed for the longitudinal compressive strength $(\sigma 1-)$.

\section{Compression-after-Impact (CAI) Tests}

There is no standard method for the CAI testing of sandwich panels, so for this study, a modified version of ASTM D7137 (9) for the CAI testing of monolithic composite plates is used, with the panel support jig design being slightly altered to accommodate the thicker panel. This approach was chosen rather than using a modification of ASTM C364 (14), which is the standard edge compression test for undamaged sandwich panels, since the latter approach does not include support for the unloaded edges of the panel, which in turn makes the panel potentially vulnerable to failure via global buckling. The test set-up for the compressive testing is shown in Figure 1. The compressive load is applied in an Instron 5500R universal testing machine, with the force-displacement data being collected using a 100 $\mathrm{kN}$ load cell. The weight of the bearing unit hanging from the load cell (and thus resting on top of the panel prior to load application) has to be accounted for in the calculations; a correction of $49.2 \mathrm{~N}$ is thus added to all of the load data. A single control test on the unloaded fixture was also performed to find the displacement of the fixture itself under load, and the appropriate correction applied to strain results.

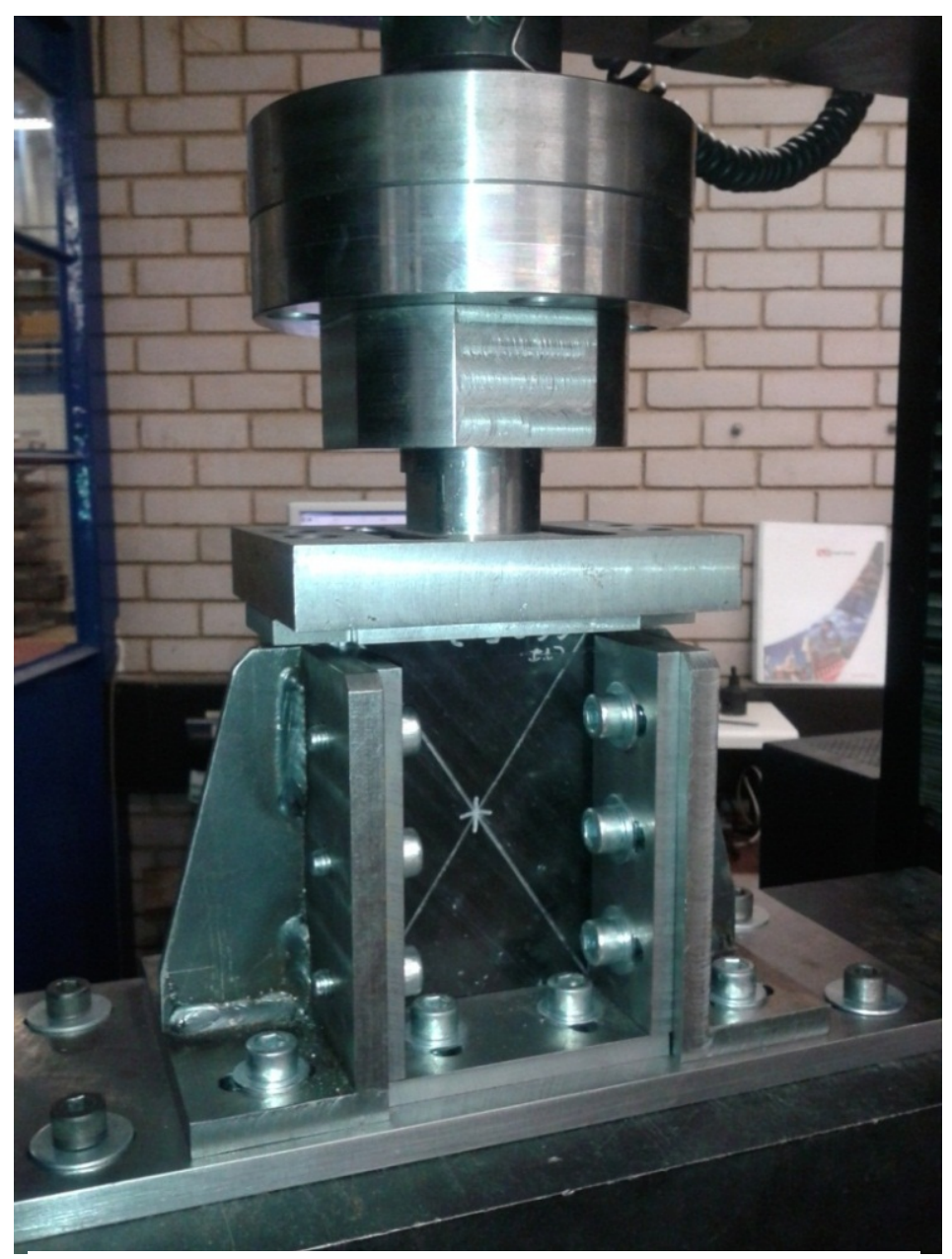

Figure 1. A panel loaded into the compression-afterimpact fixture, ready for testing 
In this study, quasi-static indentation is used rather than drop-weight testing, as simulation of impacts is a complex area of study that is of considerable research interest in its own right. A load rate of $5 \mathrm{~mm} / \mathrm{s}$ is used for the quasi-static indentation tests, comparable with Lloyd's tests on monolithic composite plates (15). The test set-up for the indentation tests in shown in Figure 2, showing the 'picture frame' support fixture that was used here. This fixture provides a 'window', giving an unsupported region of panel which is clamped around the periphery, with dimensions of $125 \times 75 \mathrm{~mm}$. A hemispherical indenter, $\varnothing 16 \mathrm{~mm}$, is used as the indenter tip. This set-up is broadly in accordance with ASTM D7136 (16), which is intended for the drop-weight impact testing of monolithic composite plates. It must be noted that this procedure just described deviates significantly from ASTM D6264 (17), for the quasi-static indentation of composite plates. However, in lieu of a standard for the indentation of sandwich panels, the method described here is an acceptable compromise that provides a good approximation of a low-velocity impact event. The applied displacements selected for the quasi-static indentation tests were $2.5 \mathrm{~mm}, 5 \mathrm{~mm}$ and $7 \mathrm{~mm}$, to give a selection of damage magnitudes, with these loads applied using an Instron 8872 machine. Sectioned (uncompressed) panels showing the three damage states through-the-thickness are shown in Figure 3.

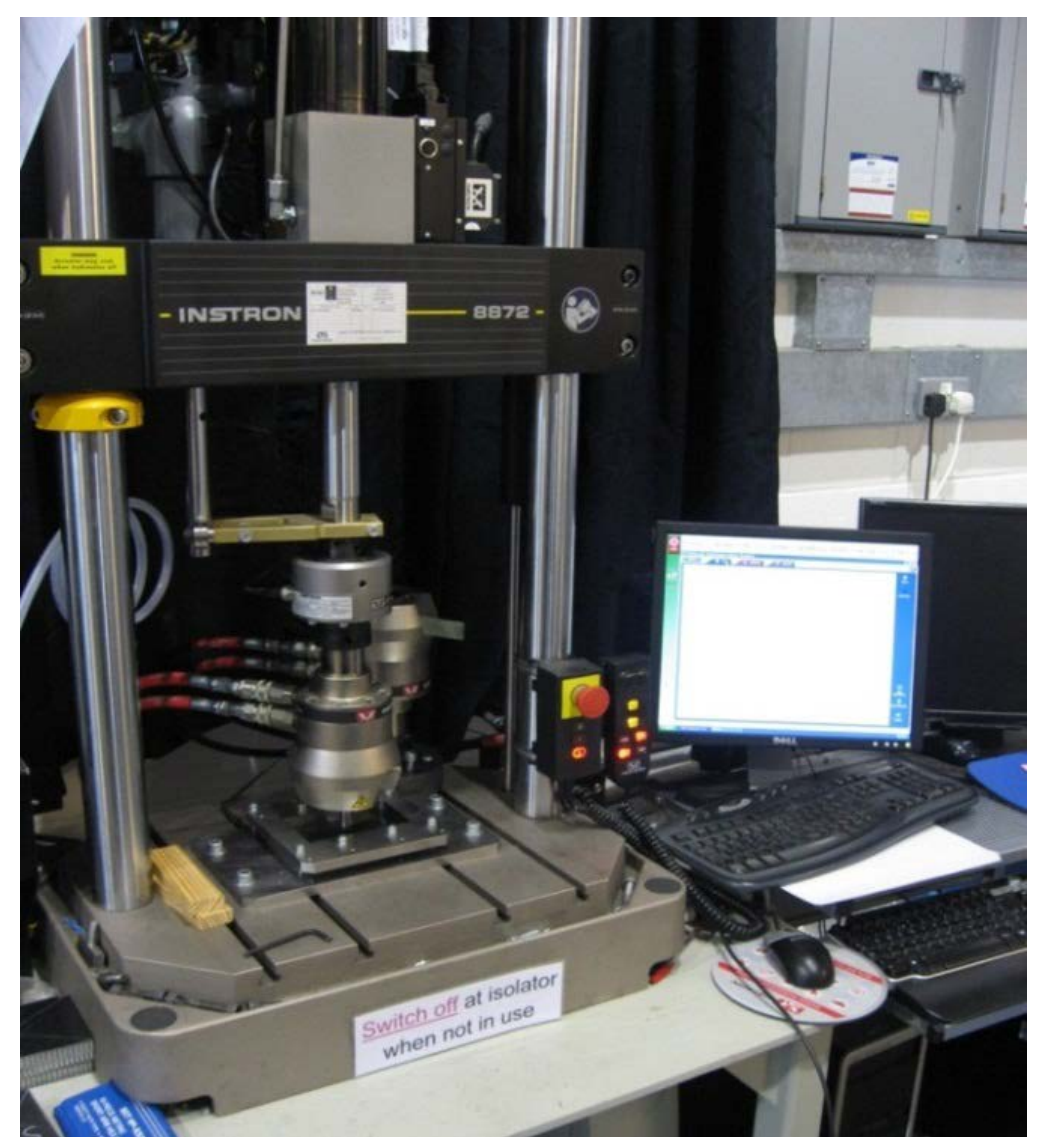

Figure 2. Indentation fixture within Instron 8872 machine 

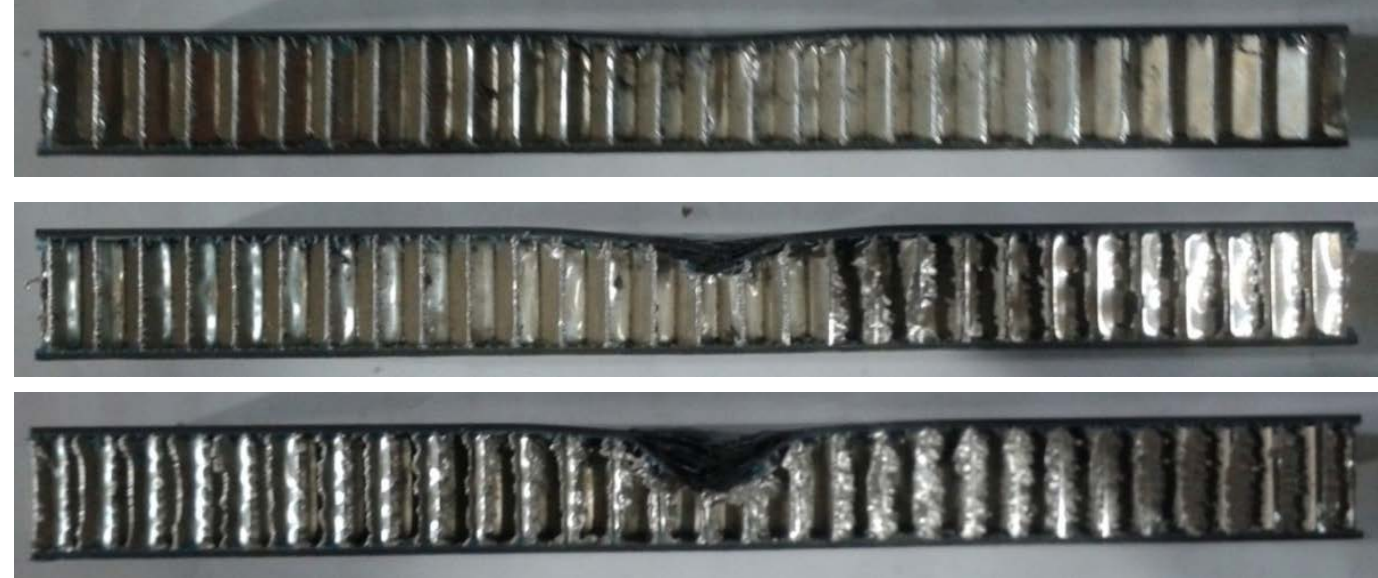

Figure 3. Sectioned symmetric panels after quasi-static-indentation with (from top) a) 2.5mm, b) $5 \mathrm{~mm}$, c) $7 \mathrm{~mm}$ applied displacement. Note the 'cup' of damaged fibres in (c) which is approximately the same diameter as the indenter $-16 \mathrm{~mm}$.

Abridged results from the compressive tests are presented in Table 1 - note that ' $S$ ' indicates symmetric panels and ' $A$ ' denotes asymmetric panels. Complete sets of data for the symmetric and asymmetric panels are given in Appendices A and B respectively. These results show a clear reduction in strength with increasing dent depth for the symmetric panels, as expected. The failure mode switches from delamination buckling to kink-band formation (18) for the $5 \mathrm{~mm}$ and $7 \mathrm{~mm}$ indentations, as the localised fibre fracture induced by these events creates an obvious weak-point from which fibre damage can propagate. Note that the $2.5 \mathrm{~mm}$ indentation events only result in a permanent dent, with no obvious fibre damage being observed.

Table 1: Results from the compression-after-impact tests

\begin{tabular}{|c|c|c|c|c|c|c|c|c|c|}
\hline Panel & $\begin{array}{l}\text { Applied } \\
\text { dent } \\
(\mathrm{mm})\end{array}$ & $\begin{array}{l}\text { Mean peak } \\
\text { indentation } \\
\text { load }(\mathrm{kN})\end{array}$ & $\begin{array}{c}\text { Mean } \\
\text { peak CAI } \\
\text { load }(\mathrm{kN})\end{array}$ & $\begin{array}{r}\text { Me } \\
\text { streng } \\
(r\end{array}$ & $\begin{array}{l}\text { CAI } \\
\text { (MPa) } \\
\text { e) }\end{array}$ & $\begin{array}{l}\text { Mean } \\
\text { residual } \\
\text { strength } \\
\text { (\%) }\end{array}$ & $\begin{array}{c}\text { Mean } \\
\text { strain at } \\
\text { failure } \\
(\%)\end{array}$ & $\begin{array}{c}\text { Mean } \\
\text { Youngs } \\
\text { Modulus } \\
(\mathrm{GPa})\end{array}$ & $\begin{array}{c}\text { Typical } \\
\text { failure } \\
\text { mode and } \\
\text { location }\end{array}$ \\
\hline SV & 0 & - & 45.06 & 259.9 & $\begin{array}{r}-38.1 \\
+36.1\end{array}$ & - & 1.27 & 31.19 & $\mathrm{D}, \mathrm{E}$ \\
\hline S2.5 & 2.5 & 2.22 & 42.10 & 245.4 & $\begin{array}{r}-47.7 \\
+55.7 \\
\end{array}$ & 94.4 & 1.20 & 29.24 & $\mathrm{D}, \mathrm{E}$ \\
\hline S5 & 5 & 2.92 & 37.98 & 219.8 & $\begin{array}{l}-10.2 \\
+10.8 \\
\end{array}$ & 84.6 & 1.02 & 29.33 & $\mathrm{~K}, \mathrm{C}$ \\
\hline S7 & 7 & 2.93 & 34.92 & 204.3 & $\begin{array}{r}-11.0 \\
+11.1 \\
\end{array}$ & 78.6 & 0.98 & 28.04 & $\mathrm{~K}, \mathrm{C}$ \\
\hline AV & 0 & - & 36.37 & 239.9 & $\begin{array}{r}-71.2 \\
+35.1\end{array}$ & - & 1.18 & 29.79 & $\mathrm{~K}, \mathrm{E}$ \\
\hline A2.5 & 2.5 & 2.26 & 38.50 & 254.7 & $\begin{array}{r}-27.2 \\
+31.1 \\
\end{array}$ & 106.2 & 1.04 & 30.42 & $\mathrm{~K}, \mathrm{E}$ \\
\hline A5 & 5 & 2.54 & 33.08 & 216.2 & $\begin{array}{r}-22.3 \\
+14.8 \\
\end{array}$ & 90.1 & 0.97 & 29.58 & $\mathrm{~K}, \mathrm{C}$ \\
\hline A7 & 7 & 2.66 & 31.06 & 206.6 & $\begin{array}{r}-17.9 \\
+24.5 \\
\end{array}$ & 86.1 & 0.91 & 30.14 & $\mathrm{~K}, \mathrm{C}$ \\
\hline
\end{tabular}

Failure codes: $\mathrm{D}=$ delamination buckling, $\mathrm{K}=$ kink-band formation

$\mathrm{E}=$ near-end,$\quad \mathrm{C}=$ centre 
The inclusion of asymmetry in the panel has a profound influence on the strength. As expected, the virgin panels show reduced strength as compared to the symmetric panels, which are identical aside from the marginally thicker distal skin. This difference is due to a stiffness imbalance which allows for the formation of additional bending moments in the asymmetric panels during compressive loading. However, when a small dent is introduced (A2.5), the average compressive strength actually becomes greater than the virgin strength, as the geometric instability produced by the dent negates the instability due to the stiffness imbalance between the impacted and distal skins. Of further interest is that the strength of the A2.5 panels is on average only marginally lower than the strength of the undamaged symmetric panels (SV). This finding may have very interesting implications in terms of design efficiency; if it were possible to induce mild geometric imbalances in a repeatable manner, it might be possible to produce more efficient structures by reducing the amount of material required in their construction. However, it should be noted that the absolute load-carrying capacity of the asymmetric panels is lower than the symmetric panels at all damage levels, due to the slightly smaller quantity of material in the asymmetric panels.

The failure modes seen for the asymmetric panels are slightly different when compared with the symmetric panels, with the majority of panels appearing to fail via kink-band formation regardless of the amount of damage. The failure locations, however, remain the same as the symmetric panels, with the failure shifting from near the end of the panel to the centre only when fibre damage is evident in the indented skin. In the low/no damage panels, the thinner distal skin almost invariably fails first. The interesting thing to observe here, for the A5 panels, is that there appears to be a degree of competition between the two failure modes at this level of damage. One panel failed at both the centre and near the end almost simultaneously - it was not possible to establish which kink band controlled the ultimate failure of this particular sample. Another panel, while failing via delamination buckling, was showing clear evidence of kink-band propagation. In this case, the kink-band does not reach the critical length before the panel failed. Examples of both failures modes may be seen in Figure 4.

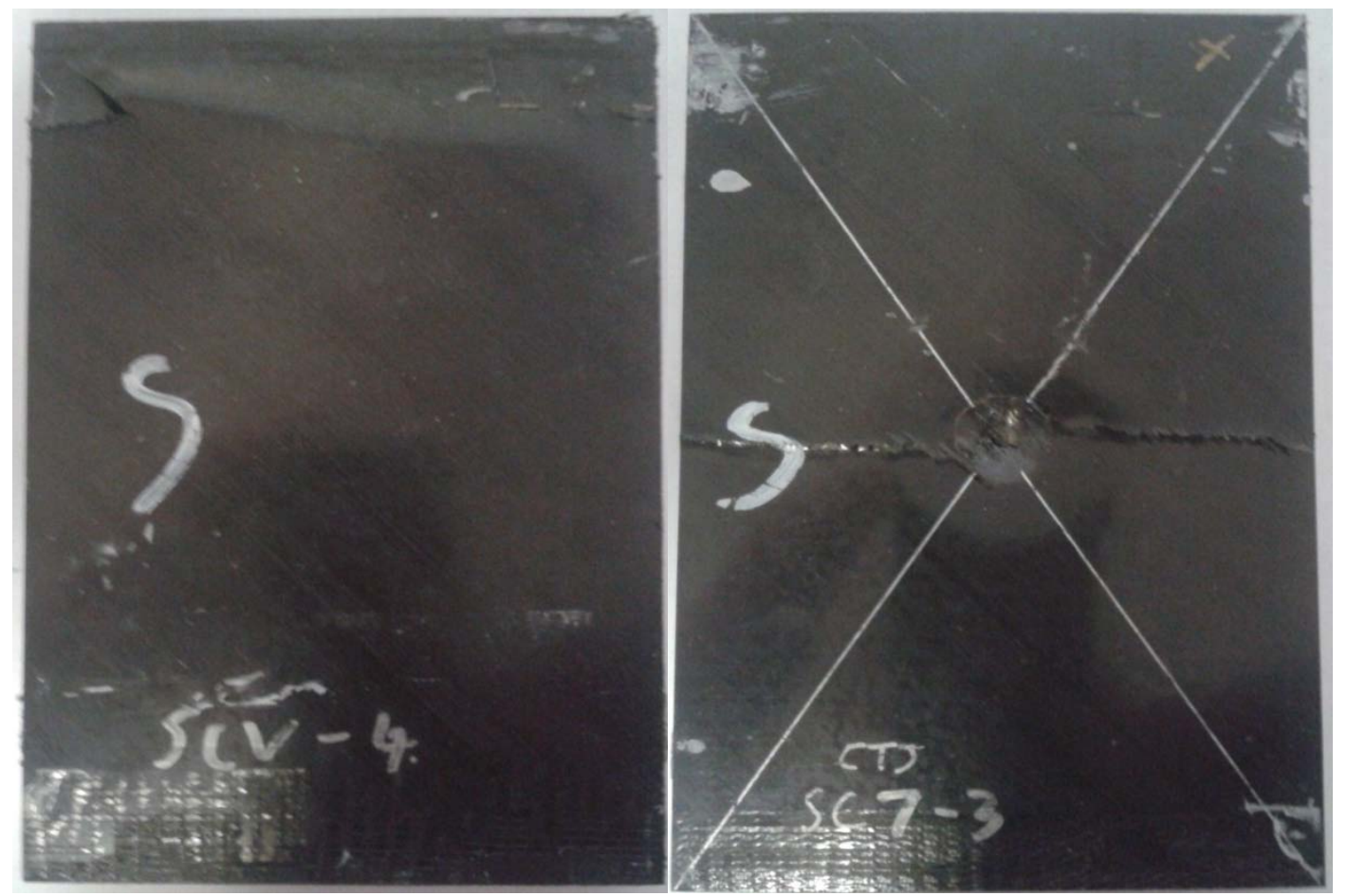

Figure 4. Failure of sandwich panels a) (left) delamination buckle towards top end of the panel, b) (right) kink-band propagation originating from the central damaged region 


\section{Numerical Model Description}

The numerical model was built using the commercial FE software package Abaqus/Explicit, and has the following features:

- The panel model has a single symmetry plane parallel to the compressive loading, so for efficiency, a half-model is used, with a symmetric boundary condition ensuring correct model behaviour. Note that in post-processing, the reaction forces must be doubled to give a true representation of the structural response.

- The analyses are performed as multistep analyses. A quasi-static transverse indentation (QSI) is applied first. The indenter is then withdrawn and finally, after a pause step to facilitate redefinition of boundary conditions, a quasi-static edge compression is applied to find the residual strength of the damaged panel. Both steps are performed using displacement control.

- All steps use a dynamic explicit solver, to ensure a robust solution during the highly nonlinear structural response arising from material damage and failure. The QSI and edge compression displacements are applied at rates of $1 \mathrm{~ms}^{-1}$ and $0.5 \mathrm{~ms}^{-1}$ respectively. These loading rates represent a significant acceleration of the problem as compared to a true quasi-static analysis. The rule-of-thumb for simulating quasi-static loadings with a dynamic solver assumes that the response of the structure is quasi-static provided that the kinetic energy does not exceed 5\% of the system internal energy (19). The peak load is taken as the point of reference for finding this ratio in both steps, as the kinetic energy will inevitably spike at ultimate load due to a loss of system equilibrium brought about by material failure. Mass-scaling, which selectively increases the mass of certain elements to meet a user-defined minimum stable time increment, is used to improve computational efficiency, with the solver set to alter the mass of elements with a stable time increment less than $2.5 e^{-8} \mathrm{~s}$

- Both the initial indentation and compression-after-impact loading are applied via rigid surfaces using a general 'all-with-self' contact interaction. This allows the load and displacement history for both steps to be generated by monitoring a single node that defines the surface. The rigid surfaces have small masses applied to the controlling nodes, to enable their use with the explicit solver, while minimising the effect of inertia.

- A single cohesive surface interaction between surface pairs, forming the interlaminar interfaces for delamination prediction, is defined within the general contact definition, using the material data given in Table 2 . This is placed at the $45^{\circ} / 90^{\circ}$ ply interface closest to the free surface of the impacted skin. This location has been chosen because delamination is expected to occur at a location where there is a change in fibre orientation (20).

- The skins are perfectly bonded to the core using tie constraints. The sets used to define the tied regions are selected such that a region around the edges of the mated parts are treated as unconstrained, to avoid clashes with the boundary condition definitions.

- All boundary conditions are applied to node sets defined at the assembly level. For convenience, these sets are defined by geometry.

- Skins are meshed using 8-node general-purpose continuum shell elements with reduced integration (SC8R). The composite lay-ups are defined using Abaqus' lay-up tool, with Hashin criteria used to model laminate damage initiation and evolution (21). The core is modelled as a solid, using a homogenous orthotropic core model with crushing behaviour applied via a simple plasticity response. It is meshed using 8-node linear solid elements with reduced integration (C3D8R).

- The indented skin has approximately 1 element every $0.55 \mathrm{~mm}$ on average, with the mesh density increasing significantly towards the indented region. This level of refinement is 
necessary for the cohesive surface to provide a reasonably accurate description of the initiation and propagation of the delamination. Indeed, to improve the delamination prediction would require even greater mesh refinement; for composite materials, the cohesive zone whereby damage is developing will typically be tenths of a $\mathrm{mm}$ in length, and it is recommended to have at least three elements in this region to produce an accurate cohesive response $(22,23)$. The mesh size chosen is a compromise solution, giving an acceptable loaddisplacement response without requiring excessive computational resources. The two cores are meshed with approximately 1 element/mm in the through-thickness-direction to ensure a good representation of the core crushing behaviour. The distal skin has a relatively coarse mesh, as its response is only of secondary importance in this particular model. All the panel models have nearly-identical meshes with approximately 52,000 elements in total.

- The key data output is the reaction force and displacement at the compression surface's controlling node, and the system's kinetic and internal energies. Full-field data is collected for the out-of-plane displacement, the stiffness degradation in the cohesive surface, indicating delamination, and intralaminar damage, to study damage formation and progression.

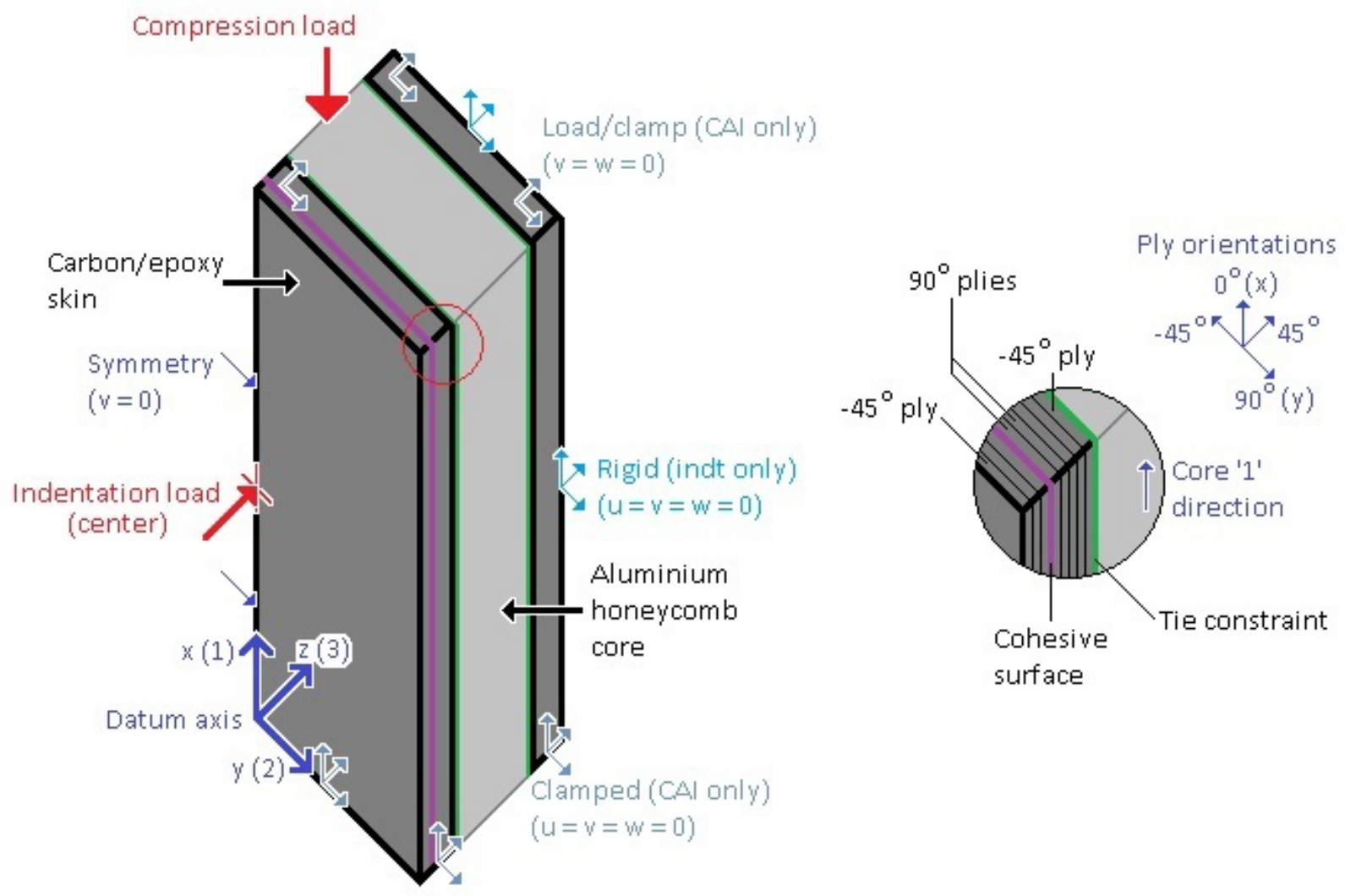

Figure 5. Schematic representation of the composite sandwich model, including boundary conditions, load and material directions and interfaces. Note that the rigid boundary condition only applies to the outer region of the panel, leaving an unsupported region in the centre to mimic the QSI fixture.

The material data for the model had to be gathered from multiple sources, often for similar (but not identical) materials, and is presented in Table 2. Data collected via the material tests mentioned previously are denoted by an asterisk in the table below. Both tensile and compressive longitudinal moduli are found by the experiments, and thus both sets of numerical results that are produced are 
presented (designated $E 1 T$ and $E 1 C$ respectively). The remainder of the strength and shear data for the skin is taken from Lloyd (15). The skin fracture energies are taken from Maimi et al (24). There is little data available in Lloyd that is applicable to the bond, with exception of the normal opening and shear opening fracture energies, and the interlaminar shear strength. The rest of the required skin data, including the mode-mix ratio used in the B-K Criterion for fracture propagation, is gathered from Camanho \& Davila (25). The in-plane properties of the core are taken from Czabaj (26). The out-ofplane core properties (including shear in the 13 and 23 directions, but excluding Poisson's ratio) and the core strength data are taken from Hill (27). The measured mean planar dimensions are used in the model, giving dimensions of $149.65 \times 99.635 \mathrm{~mm}^{2}$. The ply thickness is set at $0.107 \mathrm{~mm}$, based on the measurements for the experimental panels, and the core thickness is $12.815 \mathrm{~mm}$, with the additional thickness accounting for the two layers of adhesive bonding the skins to the core. The model is shown schematically in Figure 5. The use of multiple data sources, while unavoidable here, may prove a source of inaccuracy in the model response.

Table 2. Material Data for Numerical Model

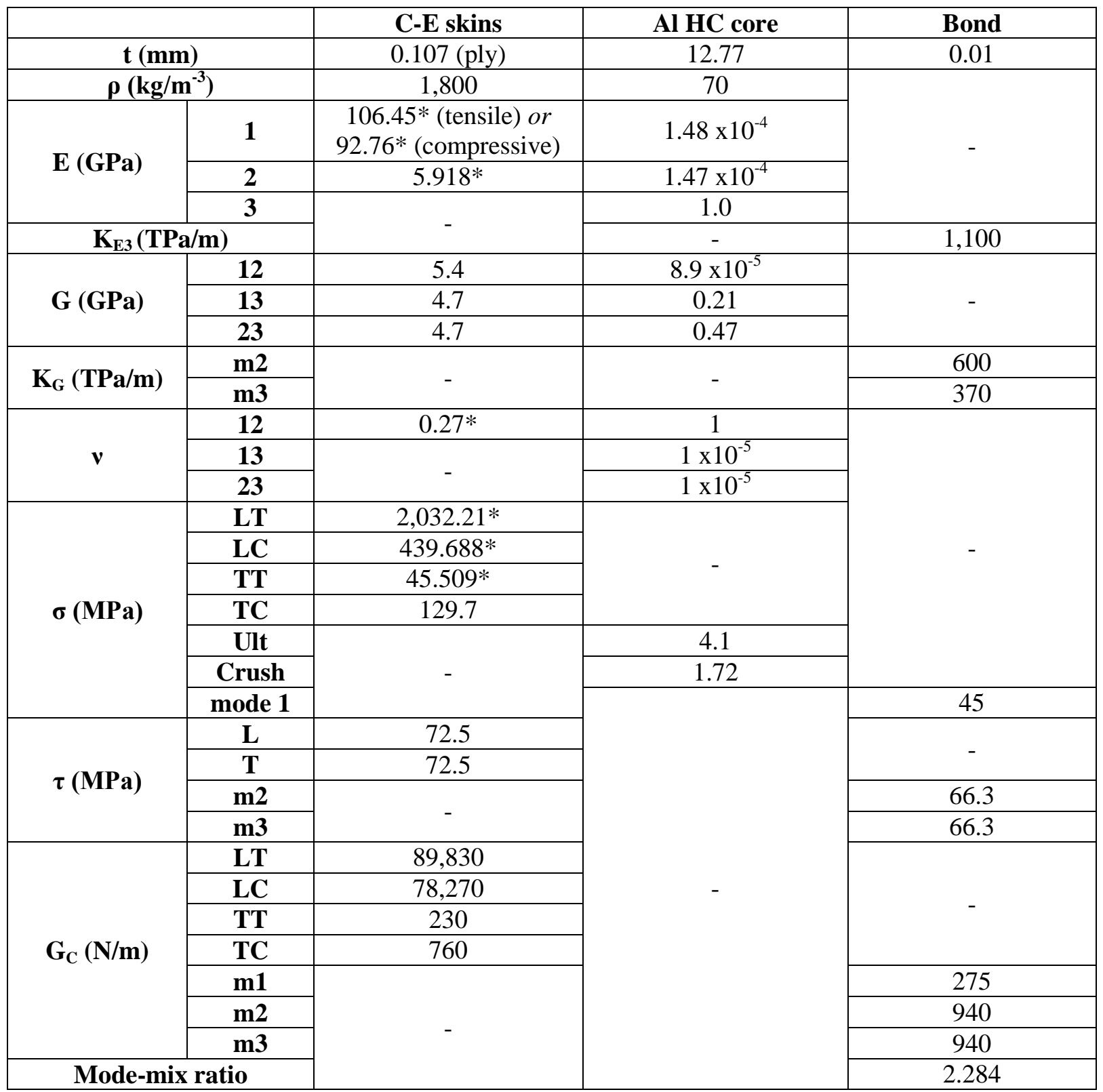




\section{Numerical Modelling Results}

A summary of the results from the models are presented in Table 3 and Table 4 for the compressive and tensile longitudinal modulus models respectively. The experimental results are restated for clarity. The CAI strength prediction show strong agreement with the experimental results for the symmetric panels at all damage levels. The strength prediction is weaker for the asymmetric panels, particularly for the low- and no-damage states, though even here the agreement with the experiments is not so poor as to compromise the validity of the model. For this configuration, the agreement with the experiments is much better at the higher damage levels, becoming comparable with (and sometimes better than) the symmetric models. The asymmetric models do not capture the increase in strength for the dented A2.5 panels (as compared with the virgin panel) that was observed in the experiments, instead showing what would be better described as insensitivity to the induced damage, even when the damage becomes highly significant. This is best seen in the negligible reduction in strength between A2.5 and A5, whereas the strength reduction between S2.5 and S5 is much more noticeable, particularly for the $E 1 C$ variation. From these results, one can conclude that the model does capture the same tendency for improved tolerance to the damage induced observed in the experiments for the asymmetric panels when compared with the symmetric panels. The percentage residual strength for the asymmetric panels is generally higher than for the symmetric panels, so the stabilising effect of the thickness asymmetry is clearly having some effect in the numerical analysis. That being said, it is also clear that the instability induced by this asymmetry has a significantly exaggerated influence in the model for lightly dented and undamaged panels.

The use of the tensile value for the Young's modulus usually increases the ultimate strength of the panels (with the notable and unexpected exception of $A 7-t$ ) as the elastic stability is increased for these panels, delaying the onset of buckling. This results in slight overestimates for the failure strength in some of the symmetric panels and improves the predictive ability of the model for the asymmetric panels, though the effect of this change on the strength of these panels is marginal (excluding $A 7-t$, as already stated). The percentage residual strength prediction is also good for both panel configurations and longitudinal stiffness inputs. This is aided by the good prediction of the undamaged panel strength for the symmetric panels, but it is noteworthy that the weaker strength estimate for the undamaged asymmetric panels does not harm the percentage residual strength estimate, further supporting the conclusion that the use of the thinner distal skin does indeed produce a balancing effect in the damaged panels.

The stress-strain response of the numerical models is not representative of the experiments. The stress-strain responses, along with the idealised, averaged stress-strain responses from the panel experiments, are presented in Figure 6 to Figure 9 for the $E 1 C$ and $E 1 T$ variations of the symmetric and asymmetric panel models respectively. First of all, the stiffness of the panels is greatly overestimated by the models, in some cases being $50 \%$ greater than the stiffness calculated via the experimental load-displacement responses when using the tensile longitudinal ply stiffness. The overestimate in the overall stiffness is significantly reduced using the compressive longitudinal modulus, but the difference still remains rather high. However, it should be noted that the experimental strain-to-failure is estimated from the displacement measurement, which, as it is an indirect method of strain measurement, may be overestimating the strain-to-failure. 
Table 3. Results from the numerical models of the experiments (E1C)

\begin{tabular}{|c|c|c|c|c|c|c|c|}
\hline \multirow[t]{2}{*}{ Model } & \multirow{2}{*}{$\begin{array}{l}\mathbf{P}_{\max } \\
(\mathbf{k N})\end{array}$} & \multicolumn{3}{|c|}{$\sigma_{\text {CAI }}(\mathrm{MPa})$} & \multicolumn{3}{|c|}{$\%$ residual strength } \\
\hline & & Num & Exp & \% error & Num & Exp & \% error \\
\hline SV-c & 41.4 & 242.8 & 259.9 & -6.6 & - & - & - \\
\hline S2.5-c & 40.8 & 239.2 & 245.4 & -2.5 & 98.5 & 94.4 & 4.3 \\
\hline S5-c & 36.4 & 213.6 & 219.8 & -2.8 & 88.0 & 84.6 & 4.0 \\
\hline S7-c & 30.1 & 176.3 & 204.3 & -13.7 & 72.6 & 78.6 & -7.6 \\
\hline AV-c & 30.3 & 2027 & 239.9 & -15.5 & - & - & - \\
\hline A2.5-c & 29.7 & 198.7 & 254.7 & -22.0 & 98.0 & 106.2 & -7.7 \\
\hline A5-c & 29.5 & 197.9 & 216.2 & -8.5 & 97.6 & 90.1 & 8.3 \\
\hline \multirow[t]{3}{*}{ A7-c } & 28.4 & 190.5 & 206.6 & -7.8 & 87.9 & 86.1 & 9.1 \\
\hline & \multirow{2}{*}{$\begin{array}{l}\delta_{\text {failure }} \\
(\mathbf{m m})\end{array}$} & \multicolumn{3}{|c|}{ Strain-to-Failure (\%) } & \multicolumn{3}{|c|}{ Stiffness (GPa) } \\
\hline & & Num & Exp & \% error & Num & $\operatorname{Exp}$ & \% error \\
\hline SV-c & 1.89 & 1.26 & 1.27 & -0.9 & 37.4 & 31.19 & 20.0 \\
\hline S2.5-c & 1.60 & 1.07 & 1.20 & -10.8 & 37.4 & 29.24 & 28.0 \\
\hline S5-c & 1.11 & 0.74 & 1.02 & -27.6 & 37.0 & 29.33 & 26.0 \\
\hline S7-c & 0.78 & 0.52 & 0.98 & -47.0 & 35.5 & 28.04 & 26.8 \\
\hline & & & & & & & \\
\hline AV-c & 1.65 & 1.10 & 1.18 & -6.5 & 41.3 & 29.79 & 38.7 \\
\hline A2.5-c & 1.20 & 0.80 & 1.04 & -23.2 & 40.9 & 30.42 & 34.4 \\
\hline A5-c & 0.90 & 0.60 & 0.97 & -38.5 & 39.2 & 29.58 & 32.5 \\
\hline A7-c & 0.81 & 0.54 & 0.91 & -40.6 & 39.8 & 30.14 & 32.0 \\
\hline
\end{tabular}

Table 4. Results from the numerical models of the experiments (E1T)

\begin{tabular}{|c|c|c|c|c|c|c|c|}
\hline \multirow[t]{2}{*}{ Model } & \multirow{2}{*}{$\begin{array}{l}\mathbf{P}_{\max } \\
(\mathbf{k N})\end{array}$} & \multicolumn{3}{|c|}{$\sigma_{\text {CAI }}(\mathrm{MPa})$} & \multicolumn{3}{|c|}{$\%$ residual strength } \\
\hline & & Num & Exp & $\%$ error & Num & Exp & $\%$ error \\
\hline SV-t & 42.8 & 249.6 & 259.9 & -4.0 & - & - & - \\
\hline S2.5-t & 42.3 & 248.2 & 245.4 & 1.1 & 99.4 & 94.4 & 5.3 \\
\hline S5-t & 40.7 & 238.5 & 219.8 & 8.5 & 95.5 & 84.6 & 13.0 \\
\hline S7-t & 30.9 & 181.4 & 204.3 & -11.3 & 72.7 & 78.6 & -7.6 \\
\hline & & & & & & & \\
\hline AV-t & 31.0 & 207.7 & 239.9 & -13.4 & - & - & - \\
\hline A2.5-t & 30.0 & 201.1 & 254.7 & -21.0 & 96.9 & 106.2 & -8.8 \\
\hline A5-t & 29.9 & 200.1 & 216.2 & -7.5 & 96.4 & 90.1 & 6.9 \\
\hline \multirow[t]{3}{*}{ A7-t } & 27.3 & 182.6 & 206.6 & -11.6 & 87.9 & 86.1 & 2.1 \\
\hline & \multirow{2}{*}{$\begin{array}{l}\delta_{\text {failure }} \\
(\mathbf{m m})\end{array}$} & \multicolumn{3}{|c|}{ Strain-to-Failure (\%) } & \multicolumn{3}{|c|}{ Stiffness (GPa) } \\
\hline & & Num & Exp & $\%$ error & Num & $\operatorname{Exp}$ & $\%$ error \\
\hline SV-t & 1.57 & 1.05 & 1.27 & -17.2 & 42.6 & 31.19 & 36.7 \\
\hline S2.5-t & 1.57 & 1.05 & 1.20 & -11.9 & 41.4 & 29.24 & 41.7 \\
\hline S5-t & 1.27 & 0.85 & 1.02 & -17.2 & 41.7 & 29.33 & 42.3 \\
\hline S7-t & 0.73 & 0.49 & 0.98 & -49.7 & 42.5 & 28.04 & 51.6 \\
\hline AV-t & 1.56 & 1.04 & 1.18 & -11.6 & 45.5 & 29.79 & 52.6 \\
\hline A2.5-t & 1.17 & 0.78 & 1.04 & -25.2 & 45.2 & 30.42 & 48.5 \\
\hline A5-t & 0.87 & 0.58 & 0.97 & -40.5 & 44.6 & 29.58 & 50.8 \\
\hline A7-t & 0.70 & 0.47 & 0.91 & -48.7 & 44.0 & 30.14 & 45.9 \\
\hline
\end{tabular}


The models do not exhibit the expected stress-strain response observed in the experiments, which is a linear elastic response leading directly into a sharp load drop due to brittle failure. Instead, the symmetric panels show bilinear, and occasionally even tri-linear, stress-strain behaviour, with all panels showing a drop in an the overall panel stiffness to a stiffness slightly less than that seen in the experiments at a strain of around $0.5 \%$ for the $E 1 C$ models or $0.4 \%$ for the $E 1 T$ models. The stiffness reduction occurs at this strain level regardless of damage level, except for the highly damaged $S 7$ models, where the stiffness reduction approximately coincides with failure. This initial softening appears to be caused by the formation of highly localised compressive matrix damage, and the initial formation of partial compressive fibre damage and cohesive surface damage. $S V$ and to a lesser extent S2.5 also show a plateau in the stress at around $0.9 \%$ strain in addition to the earlier stiffness reduction, prior to final failure. Aside from the changes in strength and stiffness already discussed, using the tensile longitudinal ply modulus has no significant influence on the response of the symmetric panels, except that the strain-to-failure of the undamaged panel is markedly reduced using this higher stiffness value. The asymmetric panels usually show a plateau in the stress at around either $0.5 \%$ or $0.45 \%$ strain for the $E 1 C$ and $E 1 T$ model variations respectively. The length of this plateau gets shorter with increasing damage, until it is essentially non-existent for A7. The strain-at-failure is usually significantly underestimated for all models (both configurations) as well, getting lower with increasing damage. Like the symmetric panel models, changing the ply stiffness has no significant influence on the response of the asymmetric models. As with the experiments, none of the numerical models experience any appreciable reduction in the initial panel stiffness due to the induced damage.

The peculiar multi-linear behaviour of the models may be due to the nature of the damage criteria used in the model, whereby damage propagates due to energy release upon reaching the specified strength thresholds. Additionally, as only a small amount of data for this particular material was collected experimentally, with the rest gathered from the literature, there is a distinct possibility that the input data is inconsistent, thus creating these anomalous stress-strain responses - this will be further investigated later in this paper. It is important to note that the deviation from the usual elasticbrittle strain-strain response for composite materials becomes less severe for all panels with increasing damage, becoming insignificant or non-existent for the $S 7$ and $A 7$ cases.

It was previously mentioned that mass-scaling has been used in this particular model to improve the computational efficiency. To check the validity of this approach, the mass-scaled models for the virgin and $2.5 \mathrm{~mm}$ indentation cases (both symmetric and asymmetric) are compared with the results from non-mass-scaled versions of these models, and these show that the use of mass scaling in this investigation has a negligible effect on the response of the panels. Crucially, the ultimate strength and the response up to this point is not changed to any appreciable degree, though the strain at the load drop does occasionally vary. Without mass scaling, the stable time increment for these panel models is typically of the order $1 e^{-8} \mathrm{~s}$, so the amount of mass scaling used here is very minor from a physical perspective, while having a significant effect on the run time, with the run time being reduced by as much as $50 \%$ in some cases. As a final check, the ratio of kinetic energy to system internal energy is checked. In the compression phase, the energy balance is always less than $0.1 \%$, and in the indentation phase the ratio does not exceed $0.5 \%$ (and is usually lower, as the internal energy is higher for the more deeply indented panels, while the kinetic energy remains effectively constant). This is well within the accepted 5\% threshold for a valid quasi-static solution (19). 


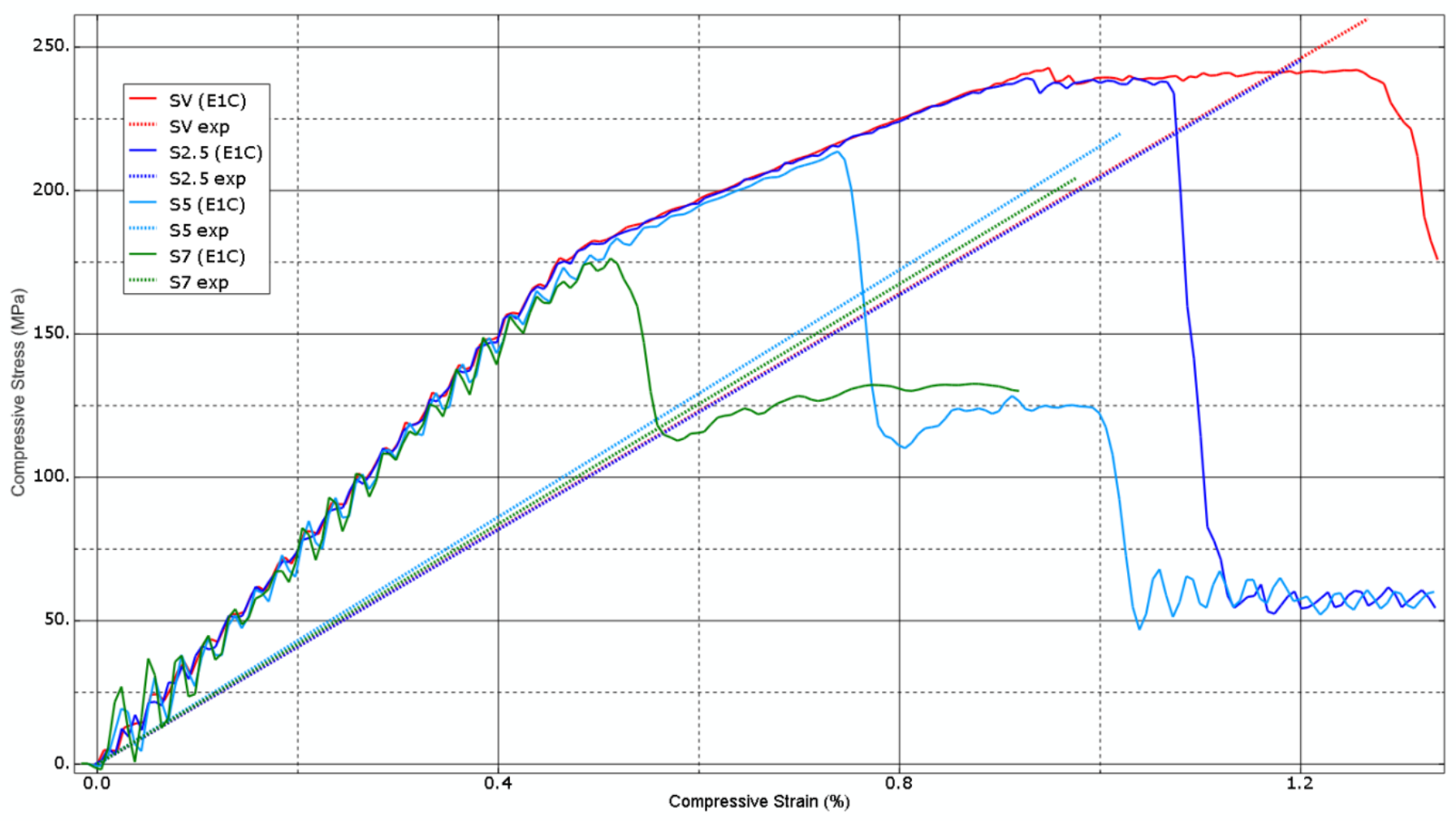

Figure 6. Stress-strain response from the numerical models (symmetric, E1C)

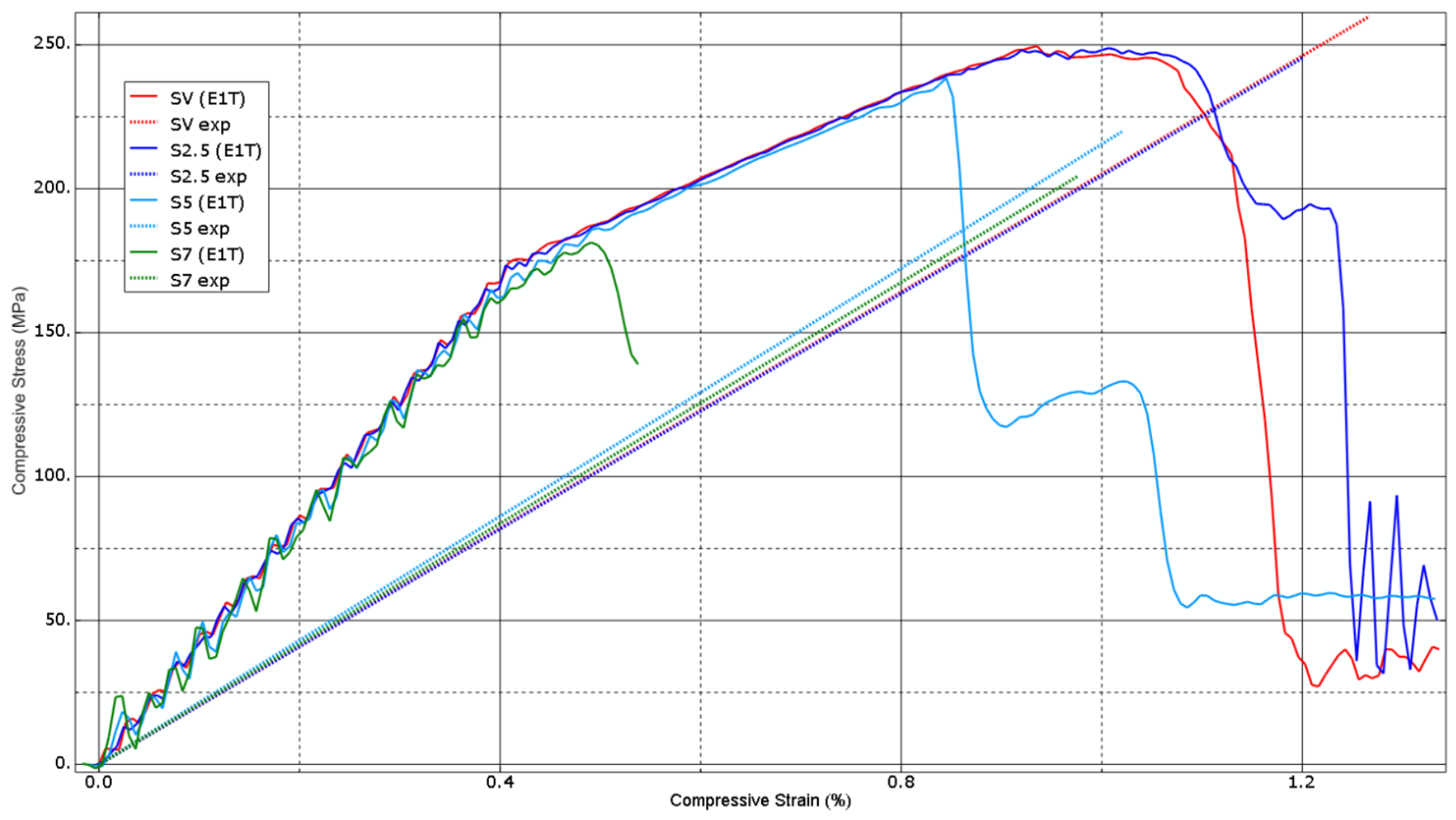

Figure 7. Stress-strain response from the numerical models (symmetric, E1T) 


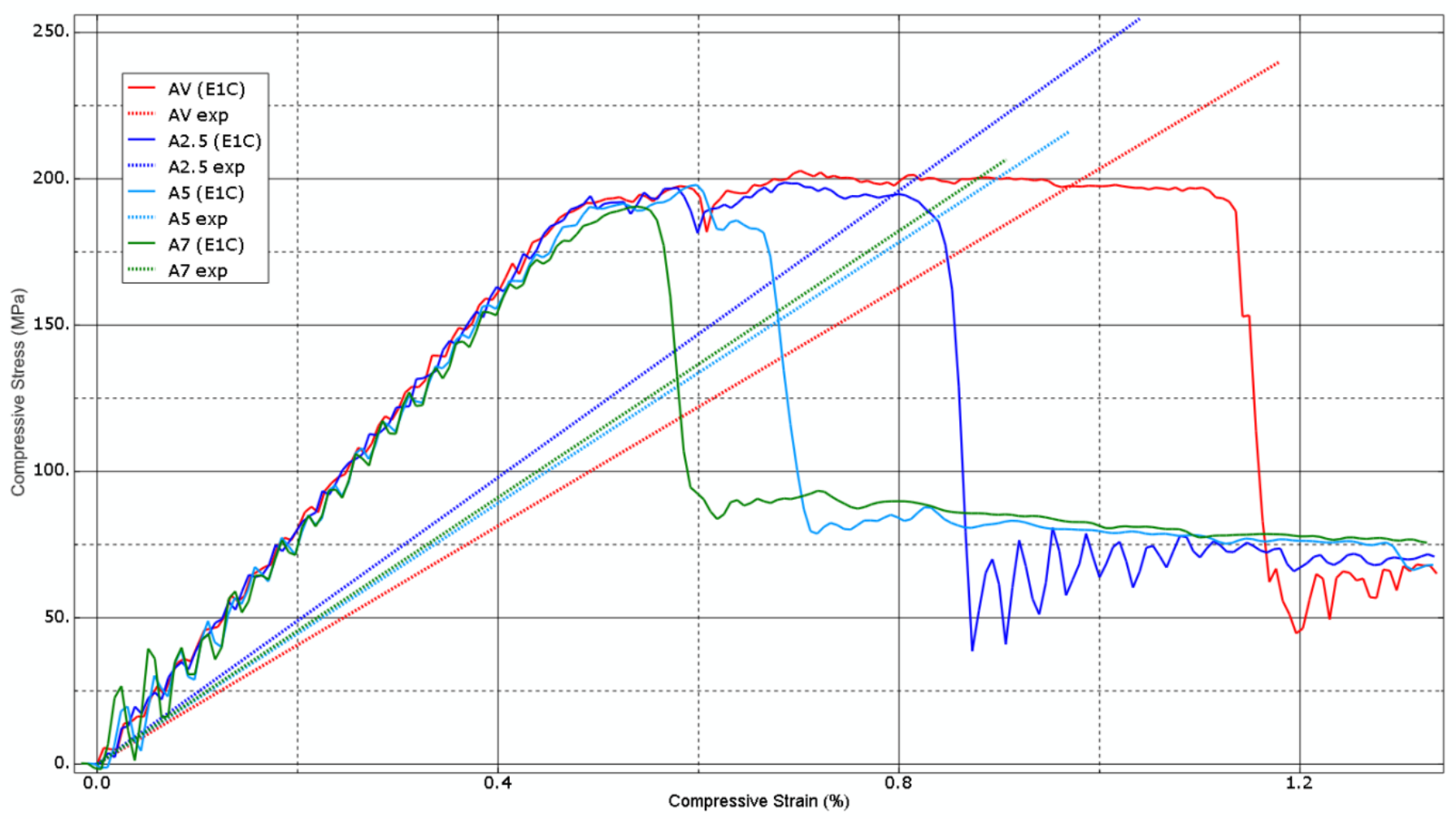

Figure 8. Stress-strain response from the numerical models (asymmetric, E1C)

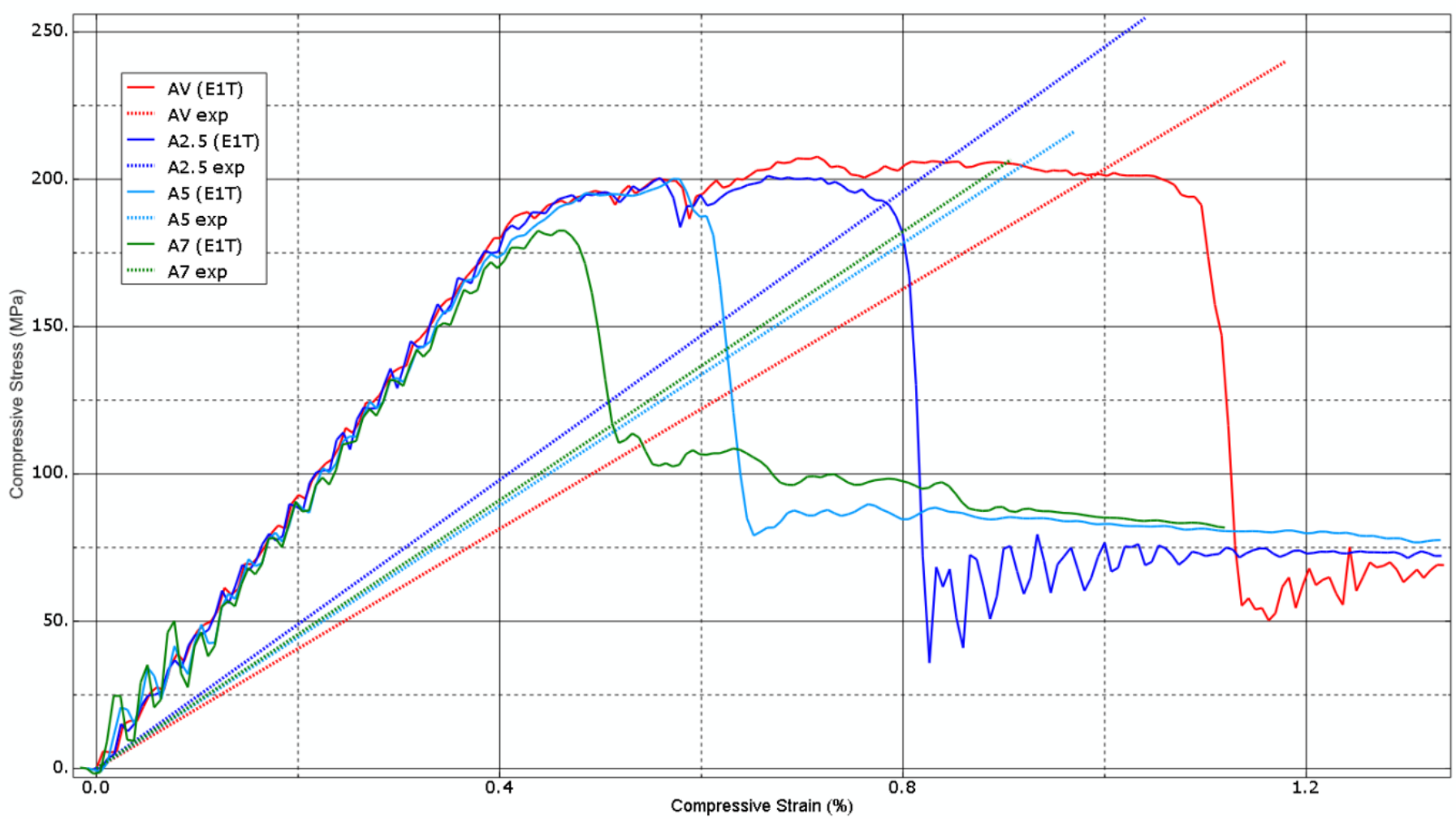

Figure 9. Stress-strain response from the numerical models (asymmetric, E1T) 


\section{Damage and Failure Progression}

The undamaged symmetric panel models show failure via a delamination buckle forming near the end of the panel, matching the experiments. However, the damaged symmetric panels all fail via the propagation of delamination buckling originating at the damaged region in the centre of the panel, with no evidence of extensive fibre damage that would indicate kink band formation. The propagation of the delamination buckle seen in the model is shown in Figure 10 for $S 7$, and is representative of all of the panels failing in this manner. The undamaged asymmetric panel fails in a similar manner to the damaged panels, with the delamination buckling originating at a random location between the loaded end and the centre line. A2.5 and A5 are also more interesting cases, with the delamination buckle originating at the damaged region as in the other damaged panels, but propagating at an angle, rather than perpendicular to the load direction. $A 7$ fails in the same manner as the damaged symmetric panels. The use of the higher longitudinal modulus in the plies does not change the nature of the final failure. Generally, the failures seen in the numerical models are a deviation from the experiments, which typically showed failure via kink band formation for the $5 \mathrm{~mm}$ and $7 \mathrm{~mm}$ indented panels, and via delamination buckling at the end for the undamaged and $2.5 \mathrm{~mm}$ indented panel. Thus, it would appear that delamination is overly influential in this particular model.
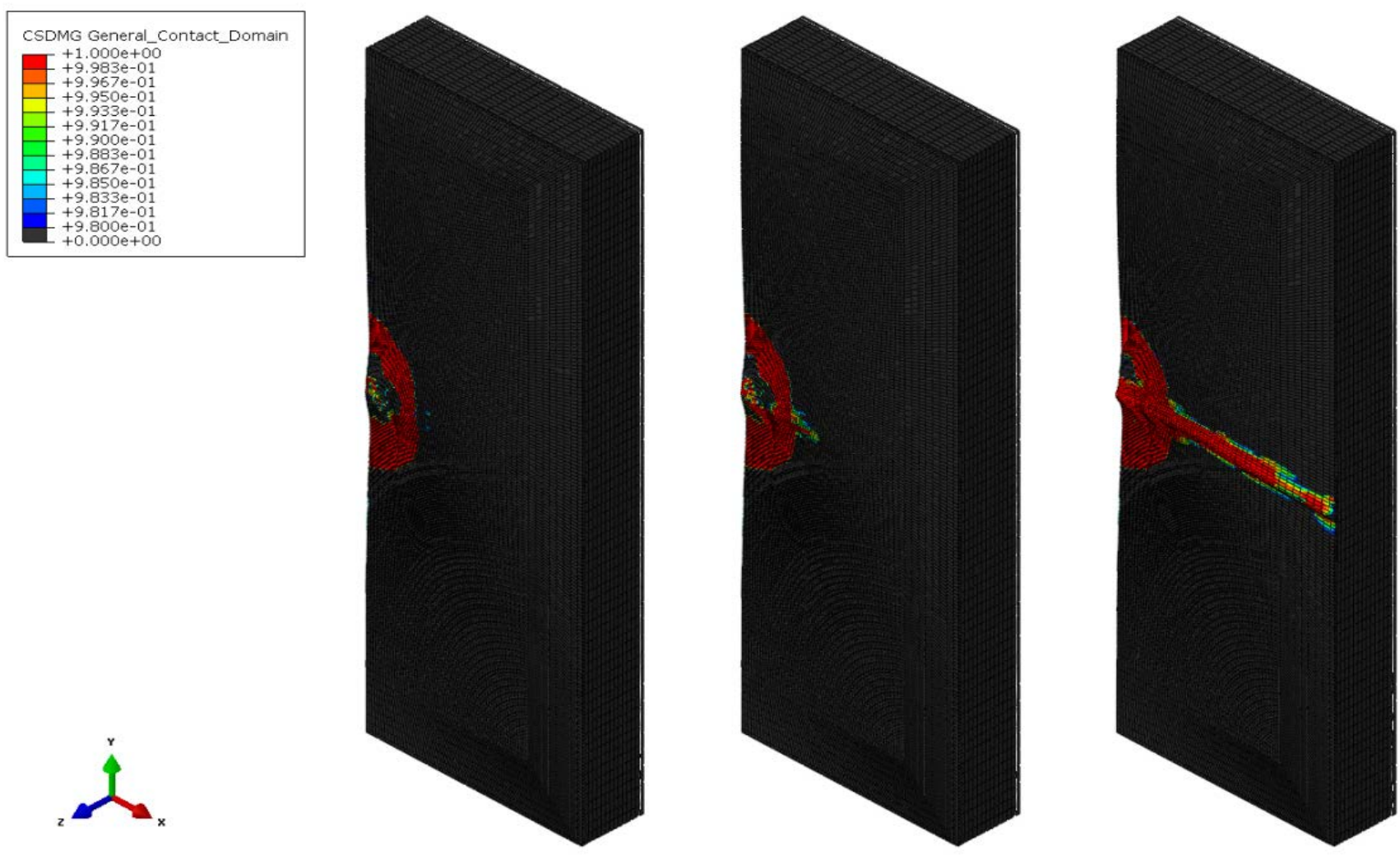

Figure 10. Delamination propagation in S7. The leftmost frame shows the panel just prior to final failure, with the delamination growing outwards from the damaged region to the fully-developed state in the rightmost frame. The delamination propagated to full-width in less than $0.2 \mathrm{~ms}$. 
Considering the post-indentation damage state (prior to applying the compressive loading), the model shows a considerable amount of global out-of-plane deformation from the indentation, which was not observed in the experiments, and it is noteworthy that the 'cup' of damaged fibres observed in the experiments (see Figure 3) is not recreated by the model. There is little evidence of extensive fibre damage even in the most severely damaged cases. Without significant fibre damage in the indented region where the indenter starts to penetrate the top skin, there is no suitable initiation point for kinkband formation, which would explain why the numerical panel models fail exclusively via delamination buckling. This observation may also explain the overestimated panel stiffness from the models. Additionally, the dent produced by the indentation bulges outwards slightly at the centre in all cases, indicating a degree of elastic recovery in the damage skin that simply wasn't present in the experimental $5 \mathrm{~mm}$ and $7 \mathrm{~mm}$ indentation cases, due to lack of local fibre breakage. The presence of the global panel deformation may also be attributed to this deficiency in the skin damage model. The relatively minor global deflection seen in the $2.5 \mathrm{~mm}$ indentation cases may actually be plausible after all there is a fairly large unsupported region in the panel during the indentation phase - but when the amount of indentation increases, the global deformation also continues to rise as the indenter fails to penetrate the top skin and create the severe localised damage that is expected. The global deflection may contribute to the tendency of the model to underestimate the ultimate strength, as the resultant geometric imperfection causes a reduction in the elastic stability of the panel, and thus increasing the likelihood of buckling. Overall, these results suggest that the utility of this model is more limited when significant skin damage occurs. A typical damage profile created in by the model is shown in Figure 11.

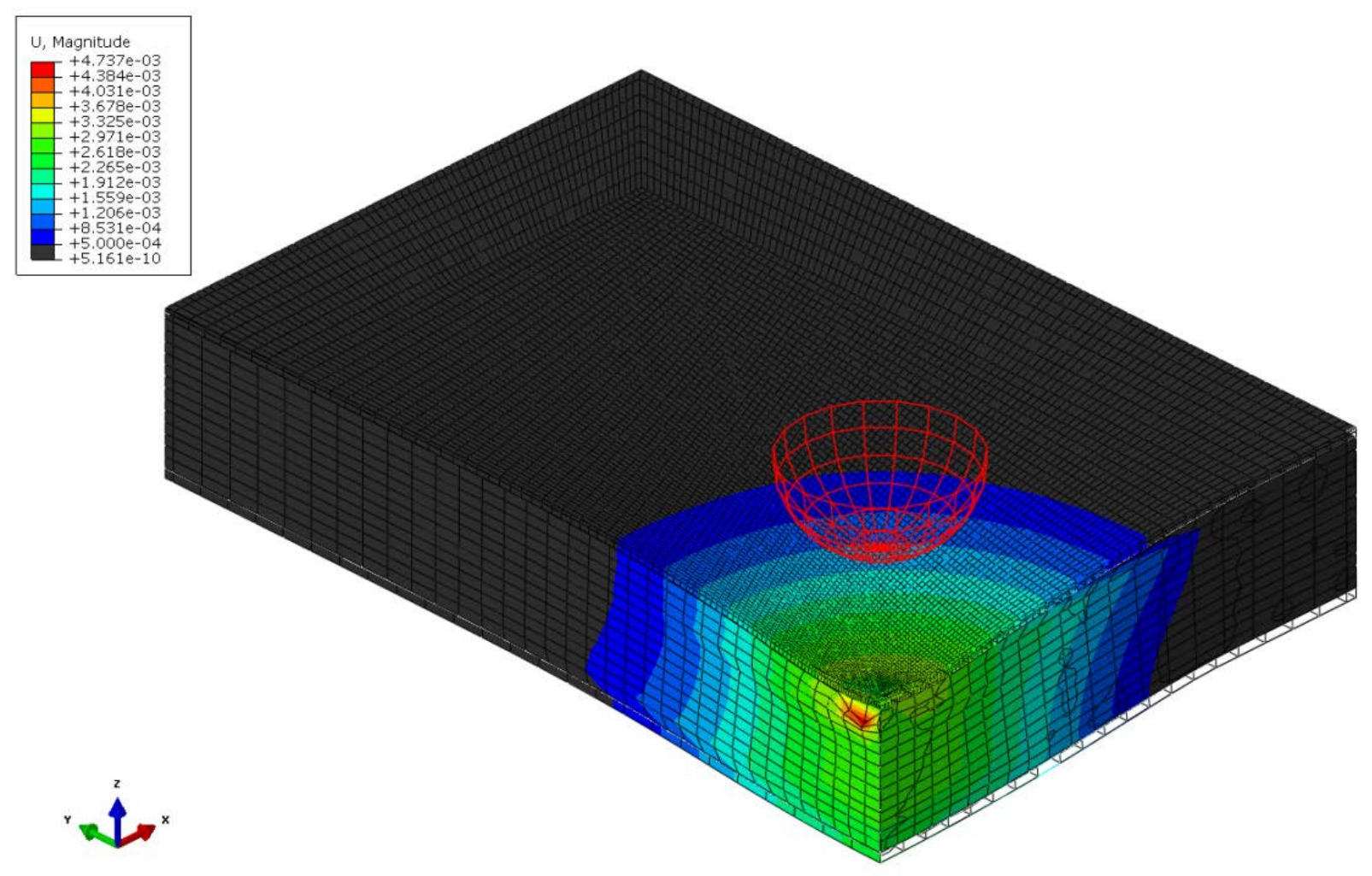

Figure 11. Damage profile for S5 


\section{Investigation of the Unexpected Stress-Strain Response}

Finally, the unexpected stress-strain responses from the numerical models are investigated, via a short parametric study. Of particular interest are the quantities not found experimentally, especially the shear strengths and stiffness, which are felt to contribute to the error in the stiffness prediction, and the fracture energies of the skin and bond layer, which may be contributing to the multi-linear stressstrain response and load plateaus seen in some of the models. The variations discussed in this section are for the virgin symmetric and asymmetric panel model, as these models showed the biggest deviation from the expected experimental shape. The results presented previously are henceforth referred to as the 'benchmark' models, and use the same designation in the graph legends as before.

Comparing the material used for this particular model and the data used by other authors for similar materials $(4,15)$ one quantity that sticks out as questionable is the longitudinal compressive strength $\sigma_{L C}$. The experimental value has been used in this model, as previously stated, but is approximately 2.5 times smaller than the values stated in other sources, while the other experimentally-derived values used for this study are broadly comparable with those in the other data sets. Thus, the first variation trialled here changes only $\sigma_{L C}$, using the value from Lloyd instead ( $\sigma_{L C}=1,032 \mathrm{MPa}(15)$ ). This variation is also trialled for the maximally damaged $7 \mathrm{~mm}$ applied indentation models, as these represent the 'worst case' situation as far as damage is concerned, though it should be reiterated that these panels did not deviate significantly from the usual elastic-brittle stress-strain response (the reduced strain-to-failure not withstanding). The results of this change for both the symmetric and asymmetric models are shown with the experimental result and the benchmark model results in Figure 12 to Figure 15, for both values of the longitudinal modulus that were found in testing.

It is clear from these plots that the markedly lower longitudinal compressive strength is the key parameter resulting in the flawed response of the benchmark models. This is particularly obvious for the virgin symmetric panels, where the use of the higher $\sigma_{L C}$ value gives an almost-textbook demonstration of the elastic-brittle behaviour expected of composite materials, and which has been observed in the experiments (see the purple traces in Figure 12 and Figure 13). The modified asymmetric panel models (the purple traces in Figure 14 and Figure 15) do not mimic the experiments quite as well, showing evidence of progressive failure that was not observed in the experiments (or at least, not nearly to the same extent), though this is still clearly a marked improvement on the plateau seen in the benchmark asymmetric models (red traces). Progressive failure of this nature, with multiple load drops prior to ultimate failure, is entirely consistent with the known behaviour of composite materials. Indeed, many of the experiments did show evidence of continued loading after the main failure, as the distal skin appeared to start carrying more load. Based on the original stressstrain plots, it is fair to presume that $2.5 \mathrm{~mm}$ and $5 \mathrm{~mm}$ indentation models using the increased longitudinal compressive strength value would fit somewhere between the undamaged and $7 \mathrm{~mm}$ indentation cases presented here.

The difficulty arises from the fact that, while increasing $\sigma_{L C}$ to a level consistent with the literature sources does result in a more realistic stress-strain response, this modification also causes the ultimate strength of the panel to far exceed that seen in the experiments. The ultimate strength predictions from the benchmark models do agree well with the experiments at all damage levels, as stated previously. This suggests that the compressive strength value found via experimentation and given in Table 2 is in fact representative of the material system used for the experiments, and actually it is the inconsistency between this and the rest of the material data gathered from external sources that is causing the erroneous structural response seen in the benchmark models. 


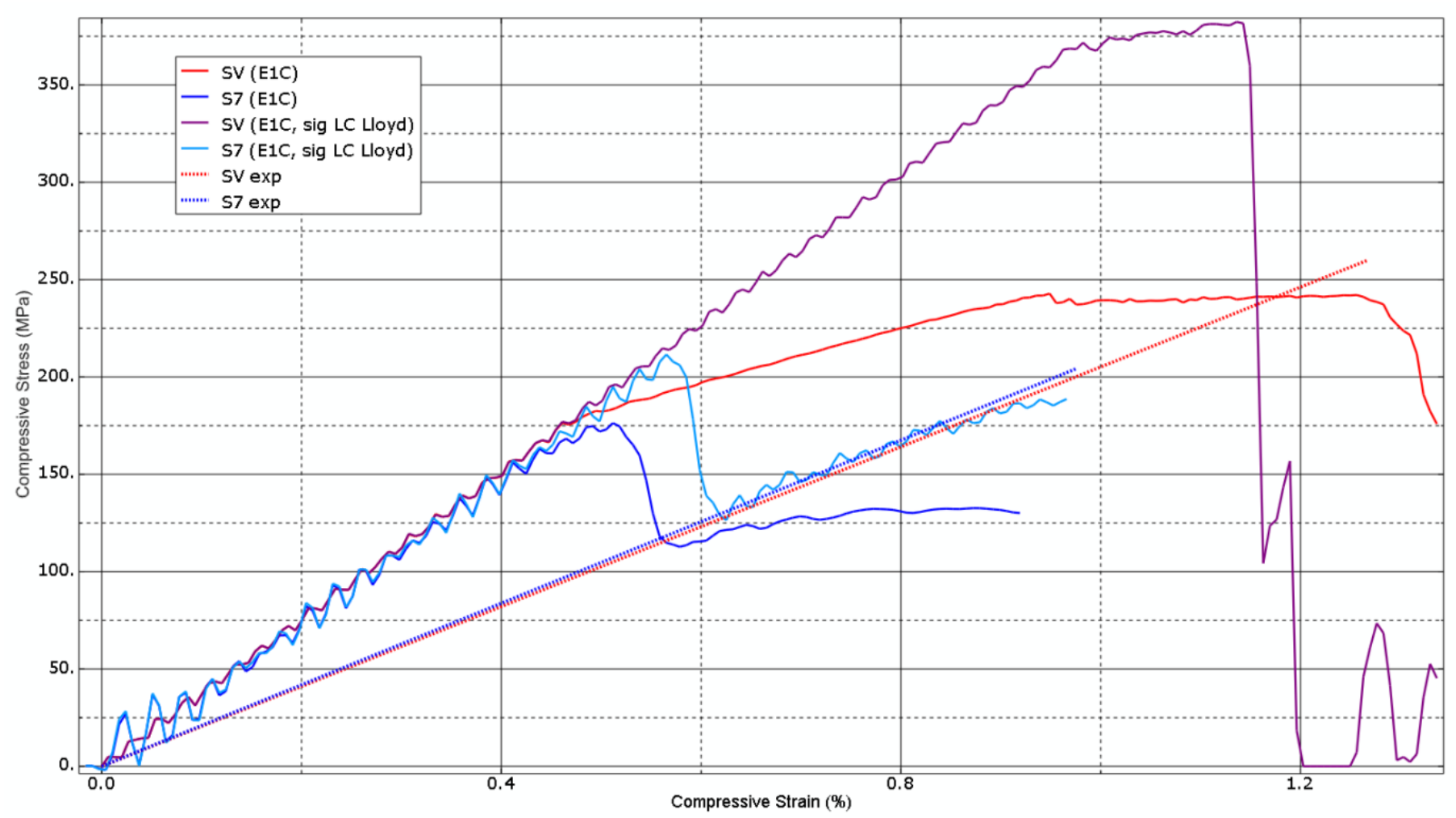

Figure 12. Stress-strain responses of symmetric panels using increased longitudinal compressive strength and compressive longitudinal stiffness

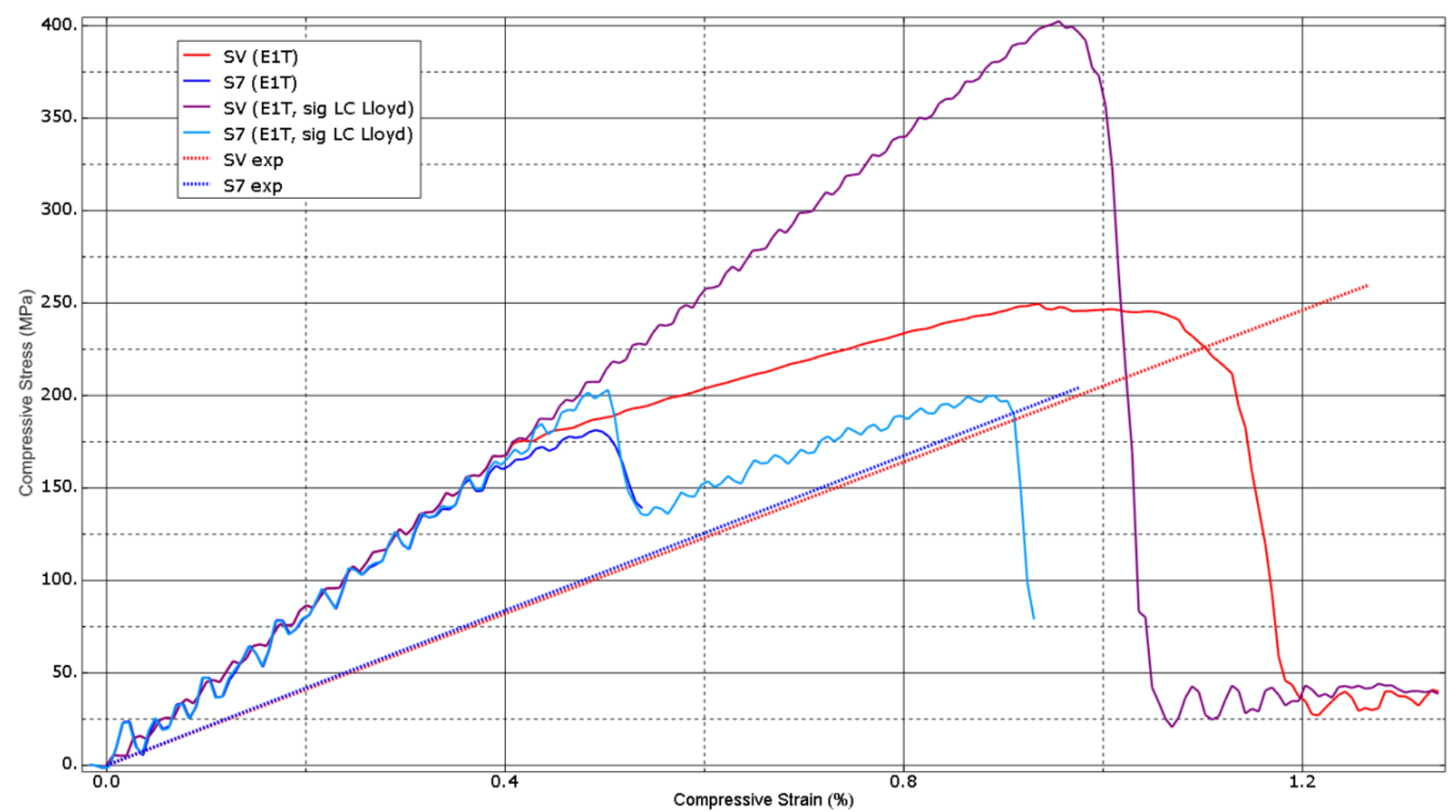

Figure 13. Stress-strain responses of symmetric panels using increased longitudinal compressive strength and tensile longitudinal modulus 


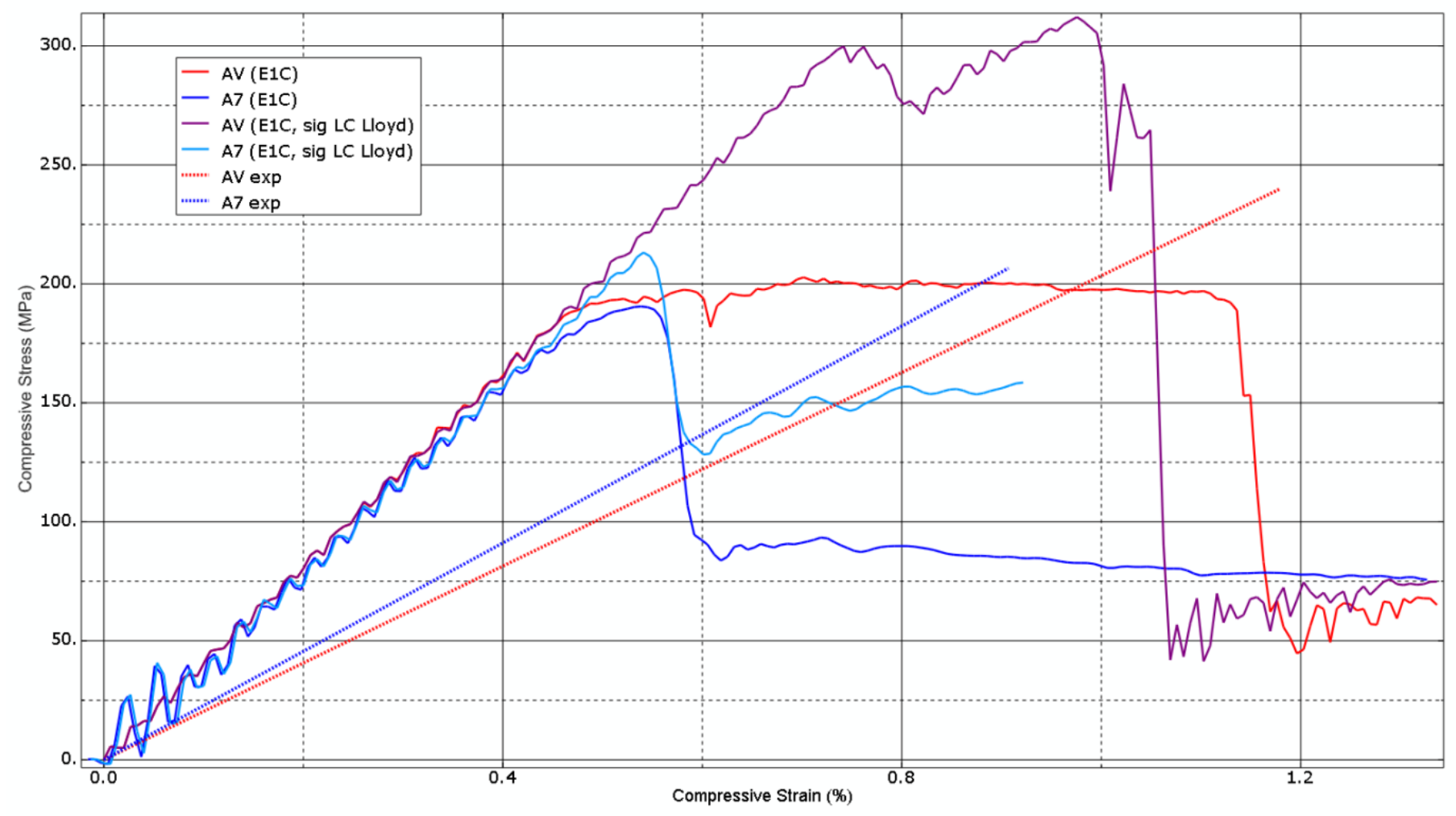

Figure 14. Stress-strain responses of asymmetric panels using increased longitudinal compressive strength and compressive longitudinal modulus

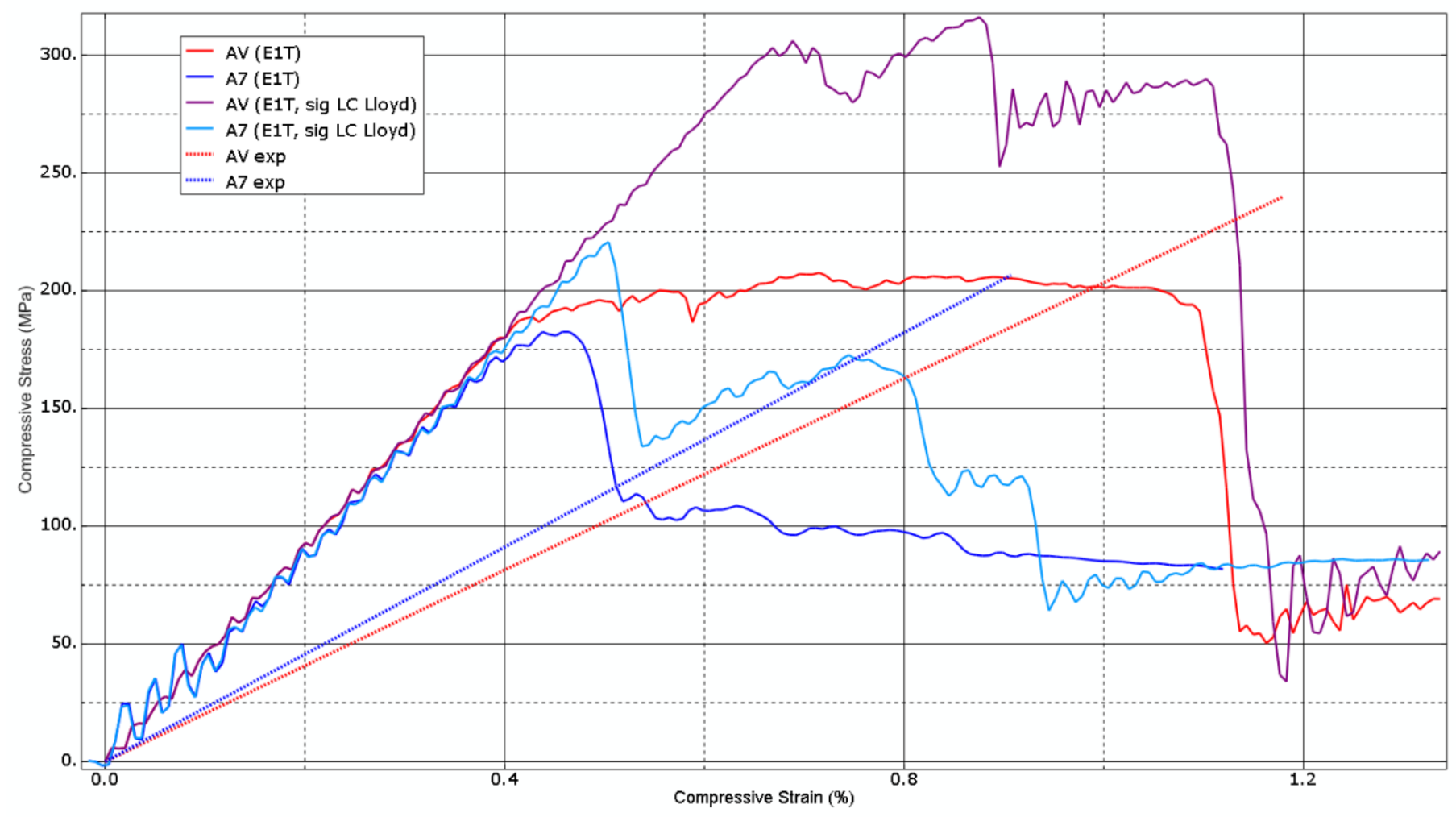

Figure 15. Stress-strain response of asymmetric panels using increased longitudinal compressive strength and tensile longitudinal modulus 
This effect is particularly significant for the symmetric models. Interestingly, the increased value for the longitudinal compressive strength has only a limited effect on the ultimate strength of the highlydamaged panels, with the modified models producing only a small over-estimate in this property when compared with the benchmark models and experiments, as the failure of these panels is dominated by other damage mechanisms, such as delamination and fibre fracture in the indentation phase. Even so, these models still show a different response to the benchmark cases, with progressive damage and failure becoming much more prominent in the modified panel models.

As the longitudinal stiffness and strength values were also found by experimentation, and thus may also be treated as representative for this material, the transverse compressive strength $\left(\sigma_{T C}\right)$ of the material is considered next, as well as the shear stiffness (in-plane and out-of-place) and shear strength. Additionally, models are trialled using reduced fracture energies in the skin and cohesive layer. Damage propagates according to the fracture energy given in the material data after the specified threshold strength is reached (21), so it is possible that an overly-high fracture energy value is causing damage to propagate too slowly prior to ultimate failure, resulting in the load plateau observed in the benchmark models. The normal-opening and shear-opening strengths are also changed in some models. Various combinations of these altered parameters are trialled, and detailed in Table 5; the designations given in the table are suffixed to the $S V$ and $A V$ panel designations (denoting undamaged panels) as required. In all cases, the specified material parameter is taken as half the nominal value given in Table 2, and the variations are performed on both symmetric and asymmetric panels.

Table 5. Material data variations

\begin{tabular}{|c|c|c|c|c|c|c|}
\hline Variation & $\sigma_{T C}$ & $\tau_{L \& C}$ & $G_{i j}$ & $G_{C \text { (skin) }}$ & $G_{C \text { (bond) }}$ & $\sigma \& \tau_{\text {(bond) }}$ \\
\hline $\mathbf{m 1}$ & $\sqrt{ }$ & & & & & \\
\hline $\mathbf{m}$ 2 & $\sqrt{ }$ & $\sqrt{ }$ & $\sqrt{ }$ & & & \\
\hline $\mathbf{m} 3$ & & & & $\sqrt{ }$ & & \\
\hline $\mathbf{m} 4$ & & & & $\sqrt{ }$ & $\sqrt{ }$ & $\sqrt{ }$ \\
\hline $\mathbf{m} 5$ & $\sqrt{ }$ & $\sqrt{ }$ & $\sqrt{ }$ & $\sqrt{ }$ & $\sqrt{ }$ & $\sqrt{ }$ \\
\hline
\end{tabular}

A final model (designated as $m 6$ ) is trialled that halves all of the skin and bond material parameters, with exception of $\sigma_{L C}$, Poisson's ratio and the mode-mix ratio in the cohesive surface data. The rationale behind this final variation is to observe the effect of artificially generating a consistent data set based around the longitudinal compressive strength, which while standing out as anomalously low, does at least give a good estimate for the ultimate strength of the panel. Crucially, this test treats the rest of the experimentally-derived material data as potentially suspect. In all model variations, the material data for the core is left unchanged. Note that this exercise is intended to demonstrate the effect of changing the material data on the response of the panels, in an attempt to identify where the issue in the material data might lie, so as to explain the strange stress-strain response of the model. An effort to curve-fit the numerical model results to the experimental results will not be made, as that would defeat the whole purpose of using numerical modelling as an alternative to experimentation. It is more useful instead to understand precisely which items of data the structural response is sensitive to, and the effect of this sensitivity.

The results from this investigation are presented in Figure 16 and Figure 17 for the virgin symmetric and asymmetric panels respectively (the nominal compressive longitudinal modulus is used in all cases, except $m 6$, where the value given in Table 2 is halved). From these plots, it's clear that none of the applied data changes fundamentally alter the erroneous strain-strain response of the models, $m 6$ 
being a (partial) exception that will be discussed separately. For the symmetric panel, altering the transverse compressive strength, the skin fracture energies and the bond properties ( $m 1, m 3$ and $m 4$ respectively) all seem to produce approximately the same reduction in ultimate strength. These changes also give a marked reduction in the strain-to-failure, though it should be noted that, while this mitigates the unexpected load plateau, it also results in a considerable underestimate of the experimentally-observed strain-to-failure (also note that any reduction in the ultimate strength also represents an increasing underestimate of the experimental results when compared with the benchmark models). The effect is stronger for the $m 3$ and $m 4$ cases. The bilinear response before failure is unchanged.

The behaviour of the asymmetric panel is slightly different, only registering a change in strength when the skin energies and bond properties are changed, with no accompanying reduction in the strain-to-failure. In fact, there is a paradoxical increase in the strain-to-failure seen $A V-m 4$. Conversely, changing the transverse compressive strength does reduce the strain-to-failure, but doesn't appear to influence the ultimate strength to any meaningful extent. For both panels, there is little difference between the strength results produced by $m 3$ and $m 4$, suggesting that the bond properties have a negligible effect on the overall performance of the panel. Reducing the shear modulus and strength has a noticeable effect on the response of both panels. Allowing for the influence of the altered transverse compressive strength in the $m 2$ variations, both the symmetric and asymmetric panels show a slightly less-stiff initial elastic response, slightly reduced ultimate strength and a considerable reduction in the strain-to-failure. The $m 5$ variations suggest that the cumulative effect of the above changes in the panel response are approximately additive.

The $m 6$ variations, as previously mentioned, are something as a special case as they treat the experimentally-derived material data as suspect, whereas the previous alterations only changed data gathered from literature sources, potentially for different material systems, and thus were already acknowledged as a potential source of error. The most striking result here is that the initial elastic response of the model now agrees very well with the experiments. This suggests that the longitudinal and transverse ply stiffness found in the experiments is something of an overestimate; though recall that the experimental results for the strain may themselves be overestimated. However, even this change, which is cumulative with the previous model variations (the changes in $m 6$ are added to the changes in $\mathrm{m5}$ ) does not eliminate the load plateau after maximum strength is reached, though it does at least eliminate the kink in the symmetric panel response prior to ultimate strength. Furthermore, as the panel stiffness is dramatically reduced, the elastic stability of the panel is inevitably reduced in turn, resulting in a significant underestimate of the ultimate strength when compared with the experimental result as buckling resistance drops. This therefore provides the further possibility that the ply stiffness found in the experiments is perhaps not as flawed as it appears at first glance. It is possible that the reduced longitudinal tensile strength is contributing to the reduced overall strength seen in $m 6$, though this is unlikely, given that the problem exclusively involves a uniaxial compression loading. 


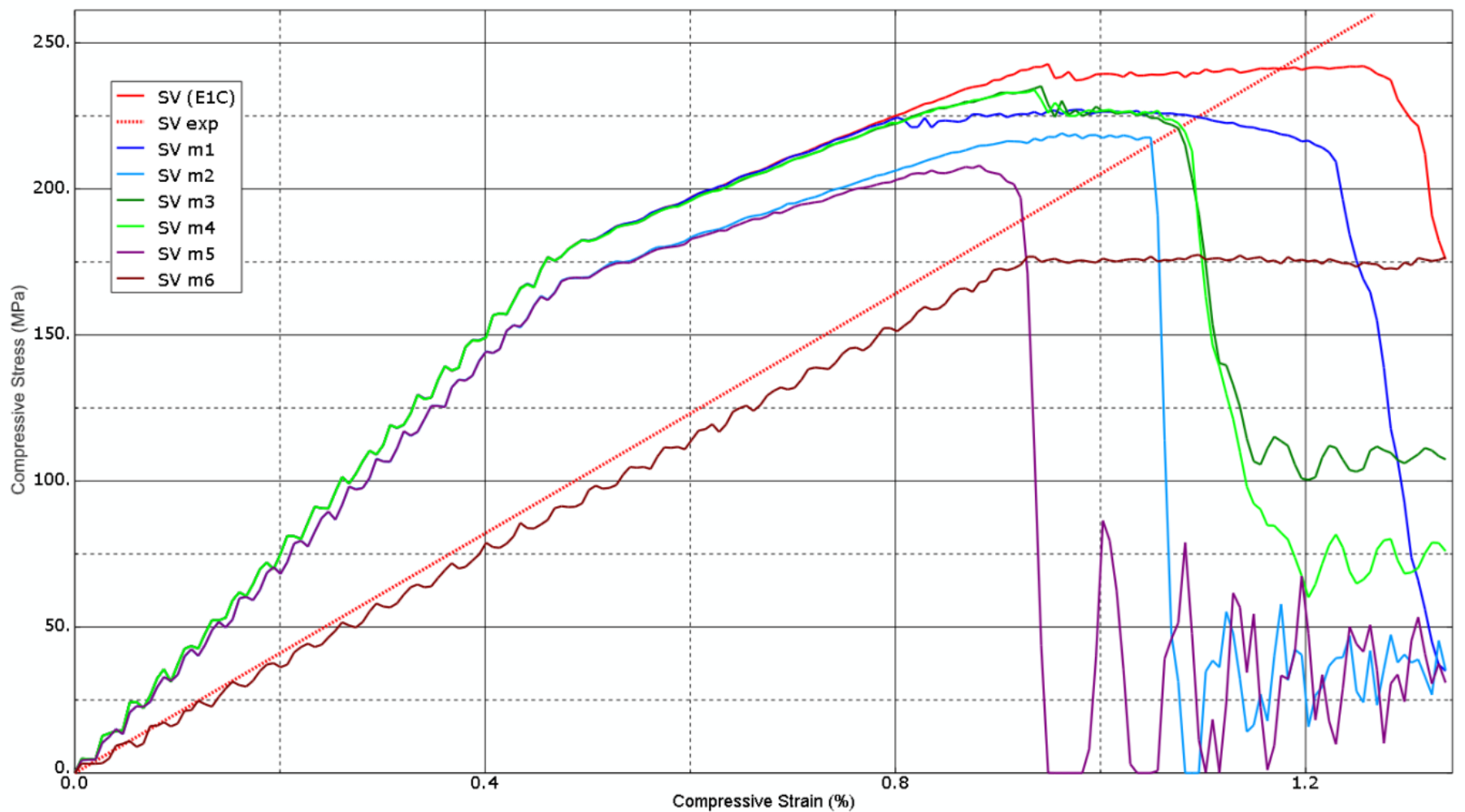

Figure 16. Undamaged symmetric panels with various changes to the material properties

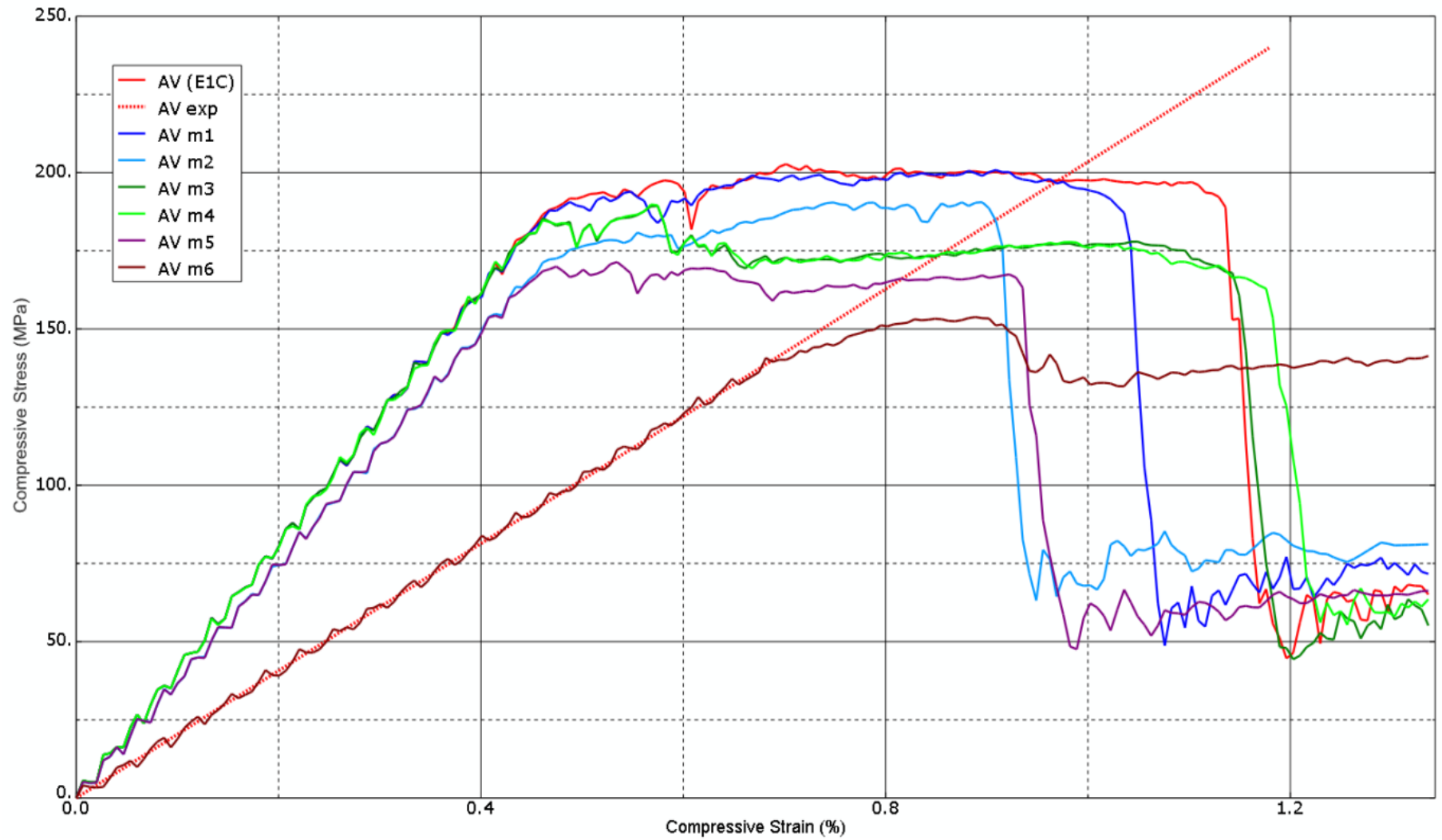

Figure 17. Undamaged asymmetric panels with various changes to the material properties 
This investigation highlights the importance of gathering a complete and coherent set of material data for the material system under consideration. While it was to a greater or lesser extent unavoidable given the constraints of this particular body of work, a certain degree of inconsistency in the data used for this model has been revealed, and it has been demonstrated that this cannot be easily corrected via small adjustments to the material parameters. It would not be reasonable to imply that certain pieces of data are unimportant, but it is fair to say that the longitudinal compressive modulus and strength are the critical parameters for achieving good results for the ultimate strength, with the other material parameters refining the response. Based on these results, future studies must include the generation of a comprehensive material data set as an essential prerequisite to numerical modelling.

\section{Conclusions}

From the experimental study, there is a clear trend demonstrating that a small amount of damage can improve the strength of sandwich panels where the distal (undamaged) skin is thinner than the damaged skin, worthy of further investigation. The numerical model gives good estimates of the residual compressive strength of both the symmetric and asymmetric panels, but shows flawed stressstrain responses due to inconsistencies in the material data-set, produced using a mix of experimentally-derived data and data collected from the literature. Future studies must ensure that a complete set of reliable data for the material system in question is collected to provide confidence in the numerical model. The model also shows notable deficiencies in the skin damage prediction, namely that it does not account for the localised fibre fracture that occurs in the skin the higher levels of applied indentation. This flaw has a knock-on effect on the rest of the analysis, as global deflection becomes too significant and there is no region of damaged fibres that can serve as the initiation point for kink-band propagation, resulting in the wrong failure mechanism being observed in the more severely damaged panels. This weakness must be addressed for this model to be of more general use.

\section{Funding Acknowledgment}

This work has been funded by the Department of Automotive and Aeronautical Engineering at Loughborough University, as part of a PhD research project. 
Appendix A: Raw Compression-after-Impact Data - Symmetric Panels

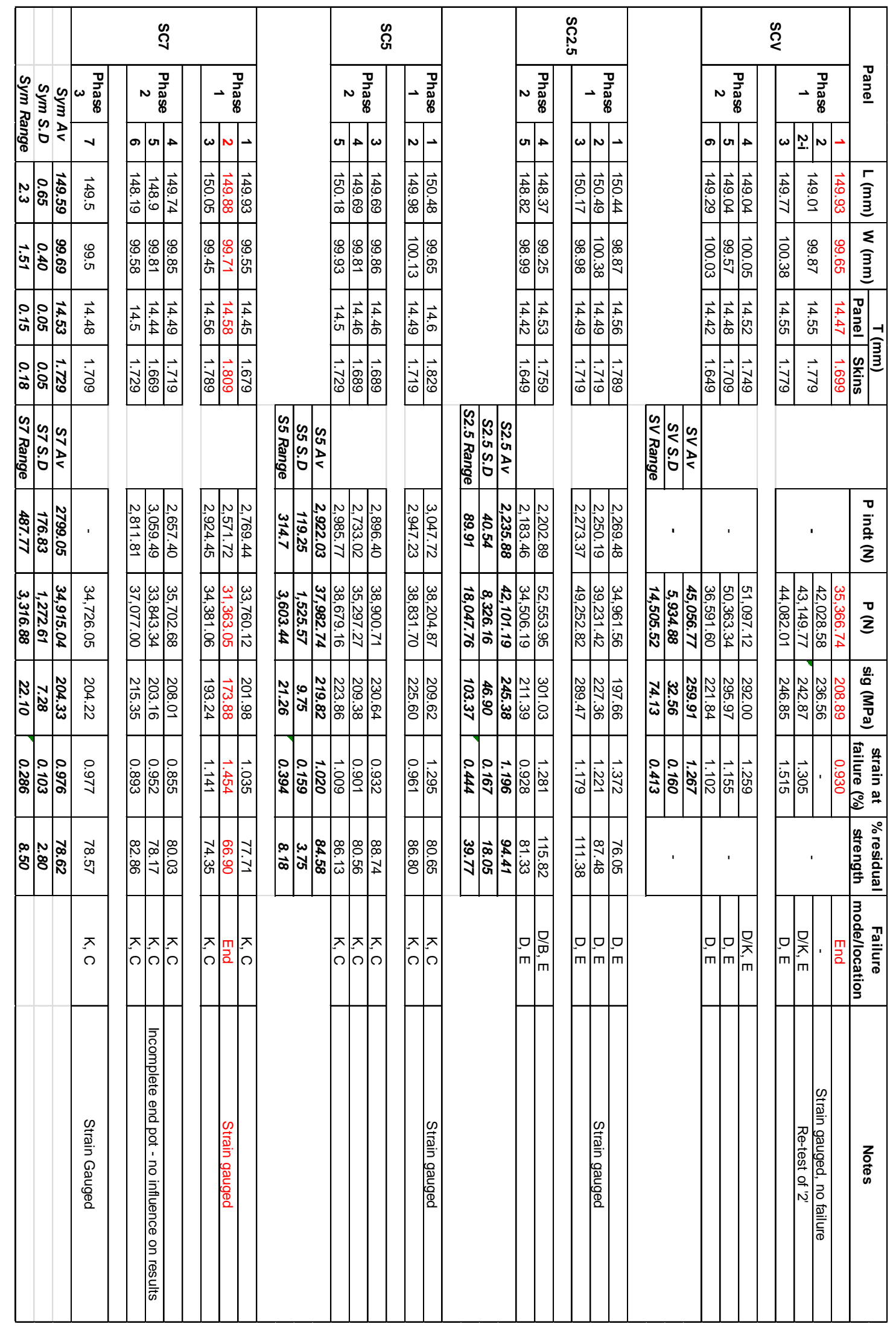

Failure codes: $\mathrm{K}=$ kink-band, $\mathrm{D}=$ delamination buckling, $\mathrm{B}=$ bending

$$
\mathrm{E}=\text { near-end, } \mathrm{C}=\text { centre }
$$


Appendix B: Raw Compression-after-Impact Data - Asymmetric Panels

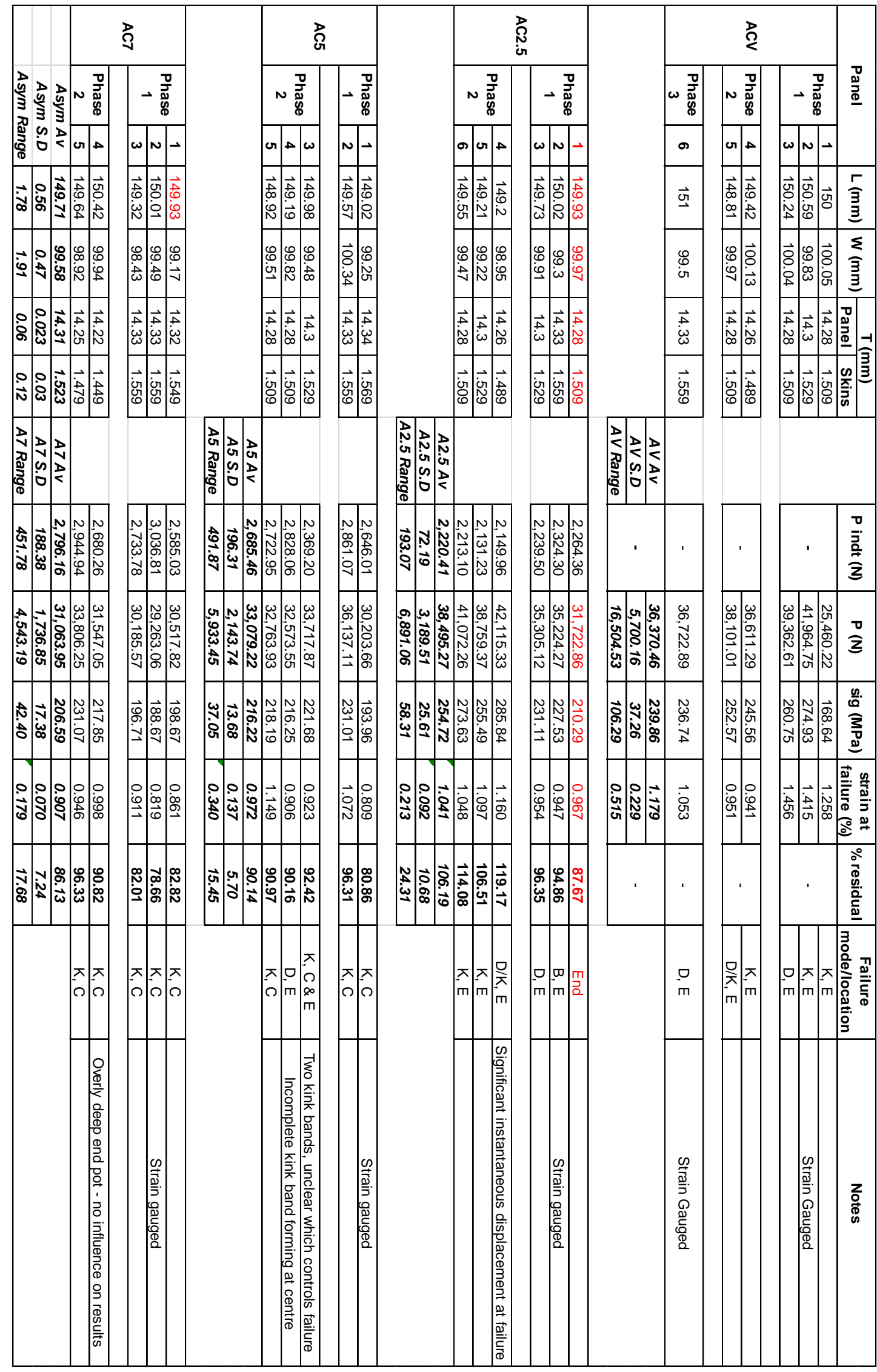




\section{References}

(1) Abrate S. Localized Impact of Sandwich Structures with Laminated Facings. Applied Mechanics Review 1997;50(2):69-82.

(2) Gonzalez EV, Maimi P, Camanho PP, Turon A, Mayugo JA. Simulation of Drop-Weight Impact and Compression after Impact Tests on Composite Laminates. Composite Structures 2012;94:3364-3378.

(3) Lacy TE, Hwang Y. Numerical Modelling of Impact-Damaged Sandwich Composites Subjected to Compression-after-Impact Loading. Composite Structures 2003;61:115-128.

(4) Compression after Impact of Sandwich Composite Structures: Experiments and Modelling. 51st AIAA/ASME/ASCE/AHS/ASC Structures, Structural Dynamics and Materials Conference; 2010; .

(5) Hinton MJ, Soden PD. Predicting Failure in Composite Laminates: the Background to the Exercise. Composites Science and Technology 1998;58:1001-1010.

(6) Soden PD, Kaddour AS, Hinton MJ. Recommendations for Designers and Researchers Resulting from the World Wide Failure Exercise. Composites Science and Technology 2004;64:589-604.

(7) Hwang Y, Lacy TE. Numerical Estimates of the Compressive Strength of ImpactDamaged Sandwich Composites. Journal of Composite Materials 2007;41:367-388.

(8) Experimental Study of In-Plane Compressive Behaviour of Unsymmetrical Sandwich Panels. 18th International Conference on Composite Materials; 2011; .

(9) Anon. Standard Test Method for Compressive Residual Strength Properties of Damaged Polymer Matrix Composite Plates. ASTM 2012;D7137 / D7137M-12:1-17.

(10) Anon. Redux (R) 609 Adhesive Film for Bonding Metallic and Composite Components Product Data. HexCel 2010:1-4.

(11) Anon. Standard Test Method for Tensile Properties of Polymer Matrix Composite Materials. ASTM 2008;D3039/D3039M-08:1-13.

(12) Anon. Standard Test Method for Compressive Properties of Polymer Matrix Composite Materials with Unsupported Gage Section by Shear Loading. ASTM 2008;D3410/D3410M03:1-16.

(13) Anon. Standard Test Method for Compressive Properties of Rigid Plastics. ASTM 2010;D695-10:1-7.

(14) Anon. Standard Test Method for Edgewise Compressive Strength of Sandwich Constructions. ASTM 2012;C364 / C364M-07:1-8.

(15) J. C. Lloyd. Impact Damage and Damage Tolerance of Fibre Reinforced Advanced Composite Laminate Structures; 2002. 
(16) Anon. Standard Test Method for Measuring the Damage Resistance of a FiberReinforced Polymer Matrix Composite to a Drop-Wieight Impact Event. ASTM 2012;D7136 / D7136M-12:1-16.

(17) Anon. Standard Test Method for Measuring the Damage Resistance of a FiberReinforced Polymer-Matrix Composite to a Contrated Quasi-Static Indentation Force. ASTM 2012;D6264 / D6264M-12:1-11.

(18) Predicting the Compression Strength of Impact-Damaged Sandwich Panels. ICCM 15th International Conference on Composite Materials; 2005; .

(19) Prior AM. Applications of Implicit and Explicit Finite Element Techniques to Metal Forming. J Mater Process Technol 1994;45:649-656.

(20) Barely Visible Impact Damage Evaluation of Composite Sandwich Structures. 51st AIAA/ASME/ASCE/AHS/ASC Structures, Structural Dynamics, and Materials Conference; 12-15 April 2010; ; 2010.

(21) Anon. Abaqus Analysis User's Manual (6.12). : Dassault Systemes; 2012.

(22) Turon A, Davila CG, Camanho PP, Costa J. An Engineering Solution for Mesh Size Effects in the Simulation of Delamination using Cohesive Zone Models. Engineering Fracture Mechanics 2007;74:1665-1682.

(23) Harper PW, Hallett SR. Cohesive Zone Length in Numerical Simulations of Composite Delamination. Engineering Fracture Mechanics 2008;75:4774-4792.

(24) Maimi P, Camanho PP, Mayugo JA, Davila CG. A Thermodynamically Consistent Damage Model for Advanced Composites. NASA, Langley 2006;NASA/TM-2006-214282.

(25) Camanho PP, Davila CG. Mixed-Mode Cohesion Finite Elements for the Simulation of Delamination in Composite Materials. NASA 2002;NASA/TM-2002-211737.

(26) M. W. Czabaj. Damage and Damage Tolerance of High Temperature Composites and Sandwich Composite StructuresCornell University; 2010.

(27) M. D. Hill. Damage Resistance and Tolerance Investigation of Carbon/Epoxy Skinned Honeycomb Sandwich Panels; 2007. 